\title{
Reconstitution of Halorhodopsin
}

Thomas Kong

Ph.D. Dissertation

November, 1989

\section{Department of Biophysics \\ University of California}

and

\section{Cell and Molecular Biology Division Lawrence Berkeley Laboratory \\ 1 Cyclotron Road \\ Berkeley, CA 94720}

This work was supported by the Office of Health and Environmental Research, U.S. Department of Energy under contract no. DE-AC03-76SF00098 and by National Institutes of Health Program Project Grant GM36884.

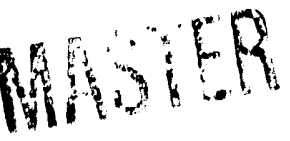


Table of contents.

Acknowledgements.

1. Abstract.

p. 1

11. Introduction.

A. General background.

p. 3

1. Bacteriorhodopsin.

a. Biochemical function. $\quad$ p. 4

b. Structural data.

p. 5

C. Mechanism of function.

p. 12

2. Halorhodopsin.
a. Biochemical function.
p. 15
b. Structural data.
p. 15
c. Mechanism of function.
p. 18

B. Aim of this dissertation.

p. 21

III. Purification of halorhodopsin.
A. Introduction.
p. 23
B. Materials and Methods.
p. 24
C. Summary for the purification of $h R$.
p. 29
D. Results and Discussion.
p. 30 
IV. Circular Dichroism study of halorhodopsin.
A. Introduction.
p. 36
B. Materials and Methods.
p. 36
C. Results and Discussion.
p. 38

V. Reconstitution of halorhodopsin.
A. Introduction.
p. 42
B. Necessity of two-dimensional crystals for electron
p. 44 microscopy.
C. Lipid composition of halobacteria membrane.
p. 44
D. Reconstitution of bacteriorhodopsin.
p. 48
1. Solubilization and recrystallization of
p. 48 bacteriorhodopsin using $\mathrm{C}_{12} \mathrm{E}_{9}$.

2. Reconstitution of bacteriorhodopsin with the purple

p. 55 membrane lipids.

E. Reconstitution of halorhodopsin.

p. 65

VI. Conclusion.

p. 72

VII. References.

p. 75 
Acknowledgements.

I would like to express my sincere gratitude to all the people who helped me through my graduate years, most notably to my advisor, Dr. Robert Glaeser, who gave so much academic and emotional support to help me finish my educational goal. Special mention should be made of Dr. Bing Jap who initiated my dissertation project and gave useful advice to carry out all the experiments done in this dissertation work.

I would also like to thank Dr. John Forte and Dr. Gary Firestone for a critical reading of the dissertation.

Ken Downing, Ed Berry, Peter Walian, Guy Perkins and Rick Burkard deserve special thanks. I always enjoyed talking with them.

Finally, I would like to thank my wife, Mi-Jeong for helping me with all small things. 
1. Abstract.

Halobacterium halobium contains a family of retinal-bound proteins; bacteriorhodopsin (bR) which mediates phototrophic growth as a light-driven proton pump, halorhodopsin ( $h R$ ) which is a light-driven chloride pump, and one or more sensory rhodopsins (sR) which mediate a phototactic response.

Much structural information has been obtained on bacteriorhodopsin through electron microscopy and spectroscopy, but the detailed proton pumping mechanism of bacteriorhodopsin is still unknown. Since halorhodopsin resembles bacteriorhodopsin in many respects, it may be possible to get a better understanding of the light-driven pumping mechanism through a comparative study of bacteriorhodopsin and halorhodopsin. Circular dichroism spectroscopy results obtained here suggest that these light-driven pumps possess nearly identical fractions of alpha helices and $B$ sheets.

Two-dimensional crystallization of halorhodopsin has been aitempted through the reconstitution of purified halorhodopsin with purple membrane lipid for electron microscopy work. The first important step for crystallization is to get a homogeneous protein which is pure and not denatured. Homogeneous halorhodopsin has been obtained by a modification of existing purification methods. Some nice looking membrane patches which have the same density as purple membrane have been obtained. But unfortunately, they are not crystalline. The procedure of $h R$ reconstitution is described in detail 
II. Introduction.

A. General background.

Halobacterium halobium is an archaebacterium that occurs in natural brines, where the $\mathrm{NaCl}$ concentration is close to saturation. Halobacterium halobium has been known to contain a retinal-binding membrane protein, bacteriorhodopsin (Oesterhelt \& Stoecknius, 1971). Under high light intensity, halobacteria utilize the proton gradient generated by bacteriorhodopsin to fuel active transport and ATP production (Dannon \& Stoecknius, 1974).

The study of mutants has revealed that Halobacterium halobium has at least two more retinal-binding membrane proteins, termed halorhodopsin ( $h R$ ) and slow or sensory rhodopsin (sR) (Lanyi, 1986; Spudich \& Bogomolni, 1988). Halorhodopsin turned out to be a light-driven chloride pump (Shobert \& Lanyi 1982). Sensory rhodopsin is supposed to be a phototaxis receptor (Spudich \& Bogomolni, 1988).

Each protein in the family possesses distinctive photochemical and functional properties but they all appear to have the same isomers of retinal linked to the amino group of a lysine residue via a protonated Schiff's base. They show a defined series of spectral intermediates in response to incident light. These photocycles arise from the chromophore-protein interaction and presumably reflect altered conformational states.

A summary of current knowledge of bacteriorhodopsin and halorhodopsin is given here as a general background, to compare the two proteins. 
1. Bacteriorhodopsin.

a. Biochemical function.

Bacteriorhodopsin $(b R)$ is an integral membrane protein that is arranged into hexagonal crystalline patches in the membrane. The patches stay intact at low salt concentration and can be isolated. The patches are known as purple membrane (PM) (Oesterhelt \& Stoecknius, 1974). Purple membrane contains only one protein, bR which constitutes $75 \%$ of its mass; the remainder is lipid, mainly phospholipid. Contamination of the purple membrane with other proteins can be as little as $0.5 \%$. The smallest repeating structural unit of the purple membrane consists of a trimer of protein with tightly bound lipid, approximately 10 lipids/bR (Blaurock \& Stoecknius, 1971) .

Several light-induced reactions have been observed in Halobacterium halobium : proton ejection from the cells, inhibition of respiration and ATP synthesis (Oesterhelt \& Stoecknius, 1973, Danon \& Stoecknius, 1974). Oxidative phosphorylation is irihibited by uncouplers and by inhibitors of the electron transport chain, but photophosphorylation is only inhibited by uncouplers, not by inhibition of the electron transport. These reactions can be explained by assuming that light can generate an electrochemical proton gradient as an energy source for ATP synthesis, even in the absence of the electron transport chain. The action spectrum for the light-induced responses corresponds to the absorption spectrum of the purple membrane. Later, the role of the purple membrane in 
pumping protons was unambiguously established by incorporating it into phospholipid vesicles (Racker \& Stoecknius, 1973).

b. Structural data.

The single polypeptide chain of bR is composed of 248 amino acids; of these more than $70 \%$ are hydrophobic (Ovchinnikov et al., 1979; Khorana et al., 1979). Bacteriorhodopsin contains no histidine or cysteine residues and the $\mathrm{N}$-terminus was shown to be a pyroglutamyl residue. There is significant clustering of regions of predominantly hydrophobic or hydrophilic residues. Within the primary structure, the retinal attachment site was assigned to 216 by the reductive fixation of the Schiff's base linkage (Bayley et al., 1981; Mullin et al., 1981).

The bacteriorhodopsin gene was found to code for an additional 13 amino acids at the $\mathrm{N}$-terminal end plus a single extra aspartic acid residue at the C-terminus (Dunn et al., 1981). There were no intervening sequences. The 13-residue leader sequence was very different from the classical pattern of $\mathrm{N}$-terminal signal peptides in secreted proteins of prokaryotes.

Image reconstruction techniques using electron microscopy by Henderson \& Unwin (1975) had shown that bR contains seven rods of density that transverse the membrane lipid bilayer region, even before the complete primary structliie of the protein had been determined. The rods were postulated to be alpha-helices based upon consideration of their size and packing density and other results obtained from $X$-ray diffraction of oriented membranes (Henderson, 1975). 
Spectroscopic techniques have also provided some insight into the secondary structure of bacteriorhodopsin. But there has been a problem in quantitating and interpreting the spectroscopic data. From UV Circular Dichroism spectra Long et al. (1977) calculated an alpha-helical content of $70-80 \%$ for $b R$, which was in agreement with the 7 alpha-helices model. In contrast, Jap et al. (1983) argue that the percentage of alpha-helical content is about $50 \%$, by using the basis function for the alpha-helix spectrum corresponding to 20 residue long helices as described by Chen et al. (1984). Jap et al. (1983) also noted a shoulder on the low frequency side of the 1665 $\mathrm{cm}-1$ band in the infrared spectrum of $\mathrm{bR}$, which indicated the presence of $B$-sheet, and they proposed a model comprising five alpha-helices and four strands of B-sheet. Although the argument based on $C D$ data may not be very convincing, the IR spectrum shows some interesting features that need explanation. The frequency of the Amide 1 band was $10 \mathrm{~cm}-1$ higher than values found for most alpha-helical polypeptides and proteins (Rothschild and Clark, 1979). Krimm \& Dwivedi (1982) proposed that alpha II type helices, in which the peptide bond planes are tilted outward from the helix axis, may explain the shift. Solid-state NMR work by Lewis et al. (1985), shows that experimentally observed data is compatible with two different structural models, first a structure consisting entirely of alpha-l helices tilted from the membrane normal and second a combination of $60 \%$ alpha-ll helix perpendicular to the membrane and $40 \%$ antiparallel B-sheet tilted from the membrane normal. To conclude, it is difficult to estimate the exact content of alpha-helices and B-sheets from the existing experimental evidence. 
From the complete primary structure of $b R, a$ detailed description of the arrangement of the polypeptide in the bilayer membrane has been tried on empirical methods. Many authors have used hydrophobicity indices (Ovchinikov et al., 1979; Engelman et al., 1980; Kyte \& Doolittle, 1982) or hydrophobic moments (Eisenberg, 1984). The prediction methods have been supported and refined by more direct experimental information; proteolytic cleavage ( Ovchinikov et al. 1979; Walker et al., 1979; Huang et al., 1980; Ovchinikov, 1982) or chemical labelling studies with membrane impermeant probes (Lemke \& Oesterhelt, 1981; Harris et al., 1979; Katre \& Stroud, 1981). In a typical representation (Fig. 21), seven helical hydrophobic rods are linked at the aqueous surface by short stretches of chain containing predominantly polar amino acid residues. The $\mathrm{C}$-terminal region probably forms the largest aqueous domain and is considered tc be disordered (Wallace \& Henderson 1982). In contrast, Renthal et al. (1983) suggested from fluorescence depolarization studies that the region is immobile and firmly bound at the membrane surface. Liao \& Khorana (1984) found that the C-terminal 17 residues were not involved in the mechanism of proton translocation. An interesting feature of the model is that there are some charged residues interspersed in some of the hydrophobic helical stretches. Although such an arrangement would appear to be thermodynamically unfavorable, charge pairing within the membrane may stabilize the structure (Engelman et al., 1980). Engelman \& Zaccai (1980) have proposed on the basis of neutron diffraction study that seven helices are arranged in such a way that the more hydrophobic residues are in contact with the lipid phase 


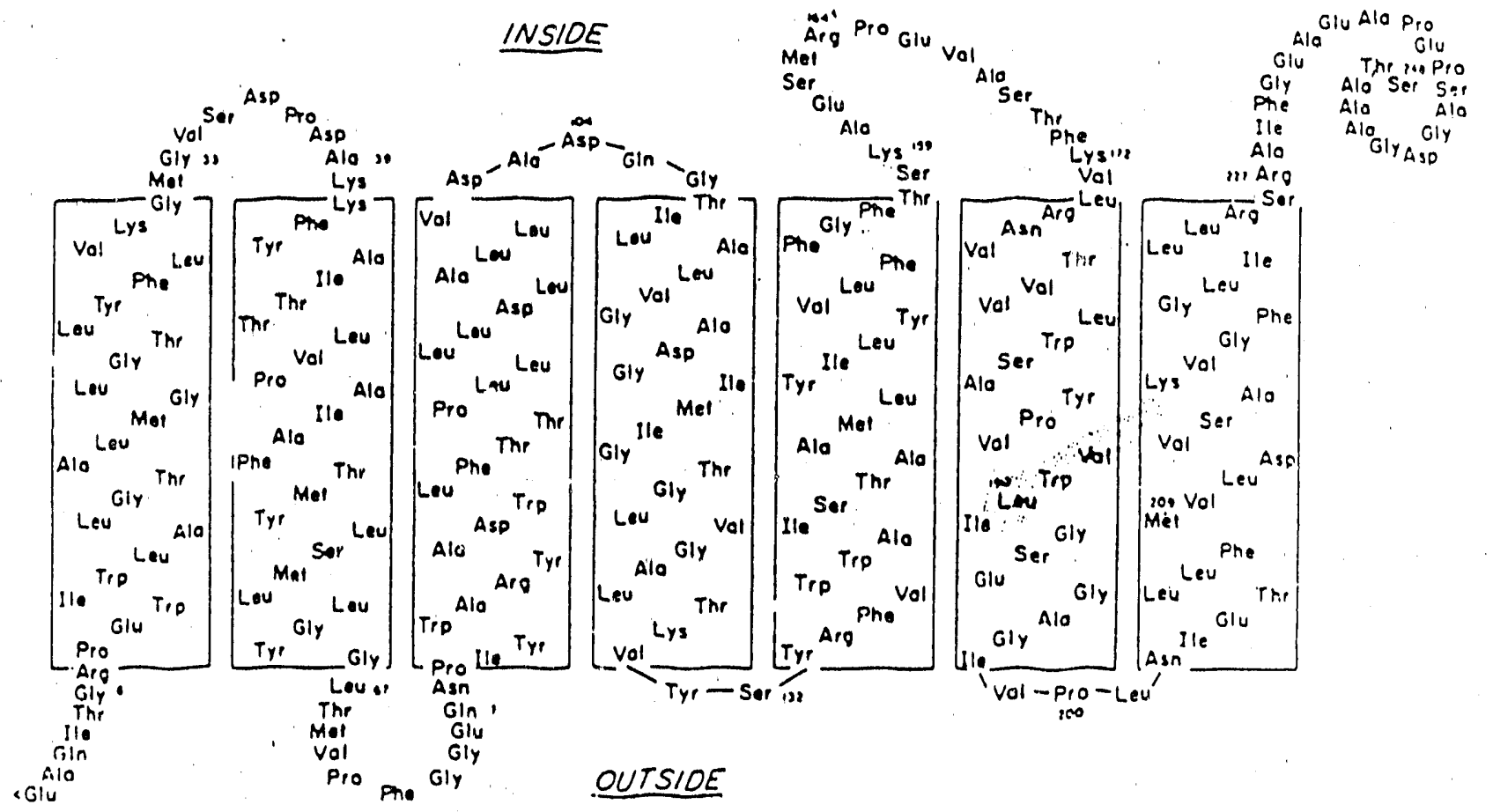

Fig. 2-1 A secondary-structure model for bacteriorhodopsin as present in the purple membrane (Huang et al., 1982). 
and the hydrophilic residues form the interhelical space. They called this structure an 'inside-o'st protein'.

The position of the retinal has been refined by neutron diffraction studies using $b R$ reconstituted with deuterated retinal. These place the B-ionone ring of the retinal near the center of the membrane (King et al., 1979). More recent diffraction studies by Seiff et al. (1986) assign the retinal site to one of two helical rods. The polyene chain is tilted at an angle of 220 relative to the membrane (Bogomolni et al., 1977). Komiya et al. (1981) have used fluorescence energy transfer to estimate that the retinal is situated near the center of the protein in an orientation such that the dipoledipole interactions with neighboring retinal residues is close to a minimum.

It is important to understand the electronic environment of the retinal-binding site, in order to explain the marked shift of the visible absorption maximum observed on the binding of retinal to the protein. Nakanishi et al. (1980) have reconstituted the chromophore with retinal analogues containing shortened chains of conjugated double bonds. The observed shifts of the visible absorption maximum fit a chromophore model with two negative charges in close proximity to the Schiff's base and the B-ionone ring. Bayley et al. (1981) have suggested that Asp-212 is positioned sufficiently close on the C-terminal helix to interact with the retinal-binding Lys-216 and so provide the counterion. Asp-115 which was shown to react with dicyclocarbodiimide on bleaching, can be a good candidate for the second charge in Nakanishi's model (Renthal et al., 1985). 
Khorana's group has prepared a number of mutants in helix 6 and 7 by site-specific mutagenesis and studied their properties by reconstitution into the correctly folded structure (Lo et al., 1984). Fig. 2-2 shows a summary of their results. There are three types of phenotypes. In the first group, such as amino acid residues 193 and 204, the protein folds and regenerates a chromophore that is identical with that of native bR. In the second class of mutants, the chromophore is regenerated, but there is a shift in the absorption spectrum of the reconstituted molecule. Here, obviously the interactions between retinal and the amino acid side chains have been affected. In the third group, no chromophore regeneration is observed. This could be due to the loss of the ability to fold or to bind retinal or to form a stable Schiff's base. On changing aspartic acid to asparagine at position 212, no chromophore regeneration is observed. It seems possible that in this case the protein does fold and forms the retinal-binding pocket, but that the Schiff's base is not tabilized because of the absence of an electrostatic interaction with the negative charge of aspartic acid. A second highly interesting mutation in the third group is the replacement of proline by leucine at position 186. Proline at position 186 is the only mutation in the third group located in helix 6 , not in helix 7 to which retinal is bound. 


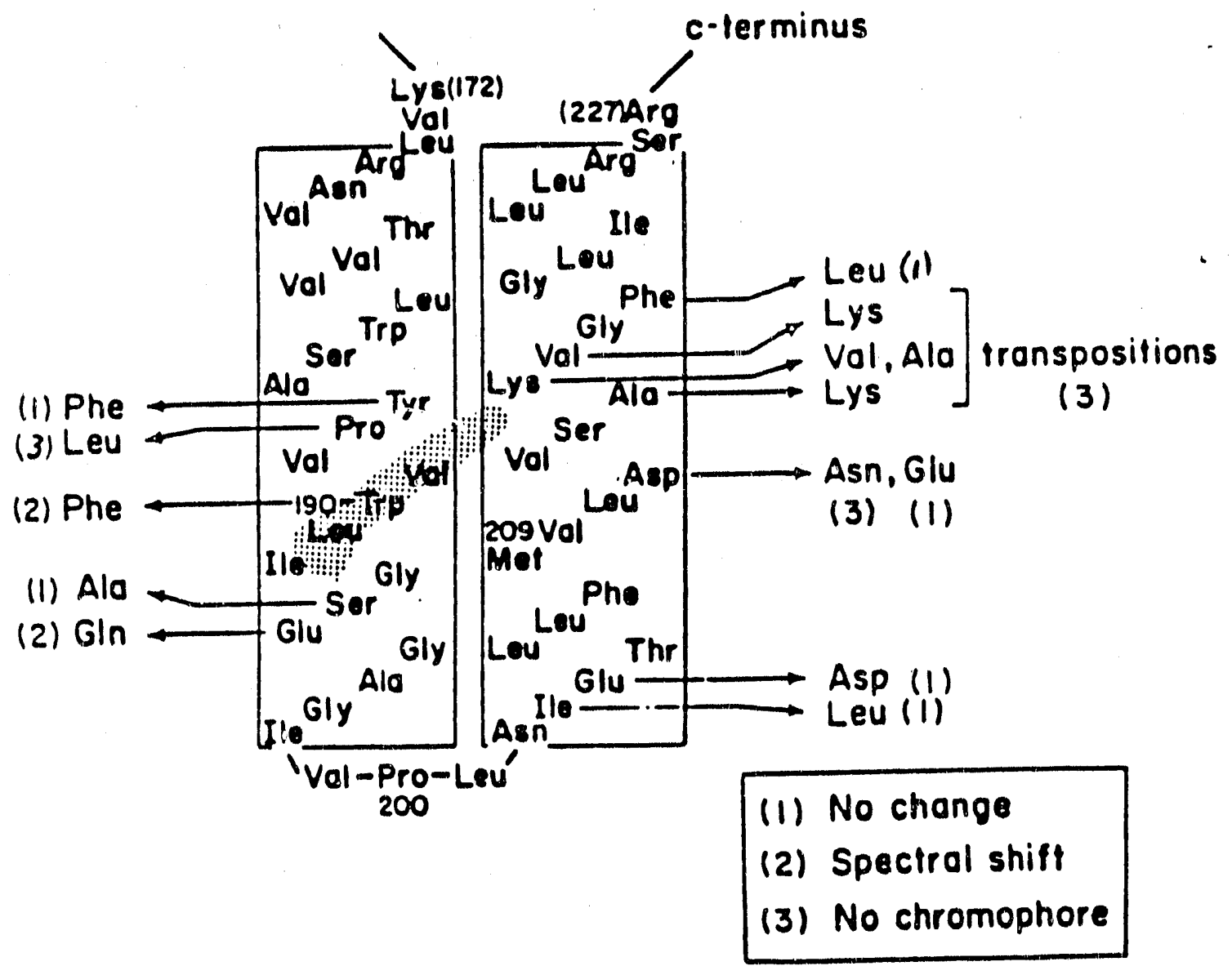

Fig. 2-2 Summary of the phenotypes of bacteriorhodopsin mutants obtained by site-specific mutagenesis (Lo et al., 1984). 
c. Mechanism of function.

A current model of the bR photocycle is illustrated in Fig. 2-3 (Fodor et al., 1988). The $\mathrm{J}$ to $\mathrm{K}_{620}$ and $\mathrm{L}_{550}$ to $\mathrm{M}_{412} 12$ steps involve trans-to 13 cis retinal isomerization and the deprotonation of the Schiff base respectively. The chromophore must then be reprotonated and reisomerized to complete the photocycle. Reprotonation of the Schiff base seems necessary in order to lower the barrier for 13 cis to trans isomerization. Reprotonation of the Schiff base and reisomerization of the retinal take place with the $\mathrm{M}_{412}$ to $\mathrm{N}$ and $\mathrm{N}$ to $\mathrm{O}_{640}$ steps respectively.

Interestingly, the structural alterations which accompany the generation of the important $M$ intermediate are not very marked in the $3.5 \AA$ electron density projection map (Glaeser et al., 1986). The difference Fourier map between $\mathrm{bR}_{568}$ and $\mathrm{M}_{412}$, shows only very small peaks, the largest of which are confined to the region of the protein. Yet, there is considerable kinetic and spectrophotometric evidence that substantial conformational changes occur during the $L$ to M transition (Kuschmitz \& Hess, 1982). Altered environments for byrosine (deprotonation) and tryptophan residues have been particularly implicated, most attention being directed to Tyr-26 and Tyr-64 whose modification abolished proton transport (Lemke \& Oesterhelt, 1981).

Several mechanisms of proton translocation have been proposed; many involving the proton of the Schiff base, but they are still speculative and without firm experimental evidence. 


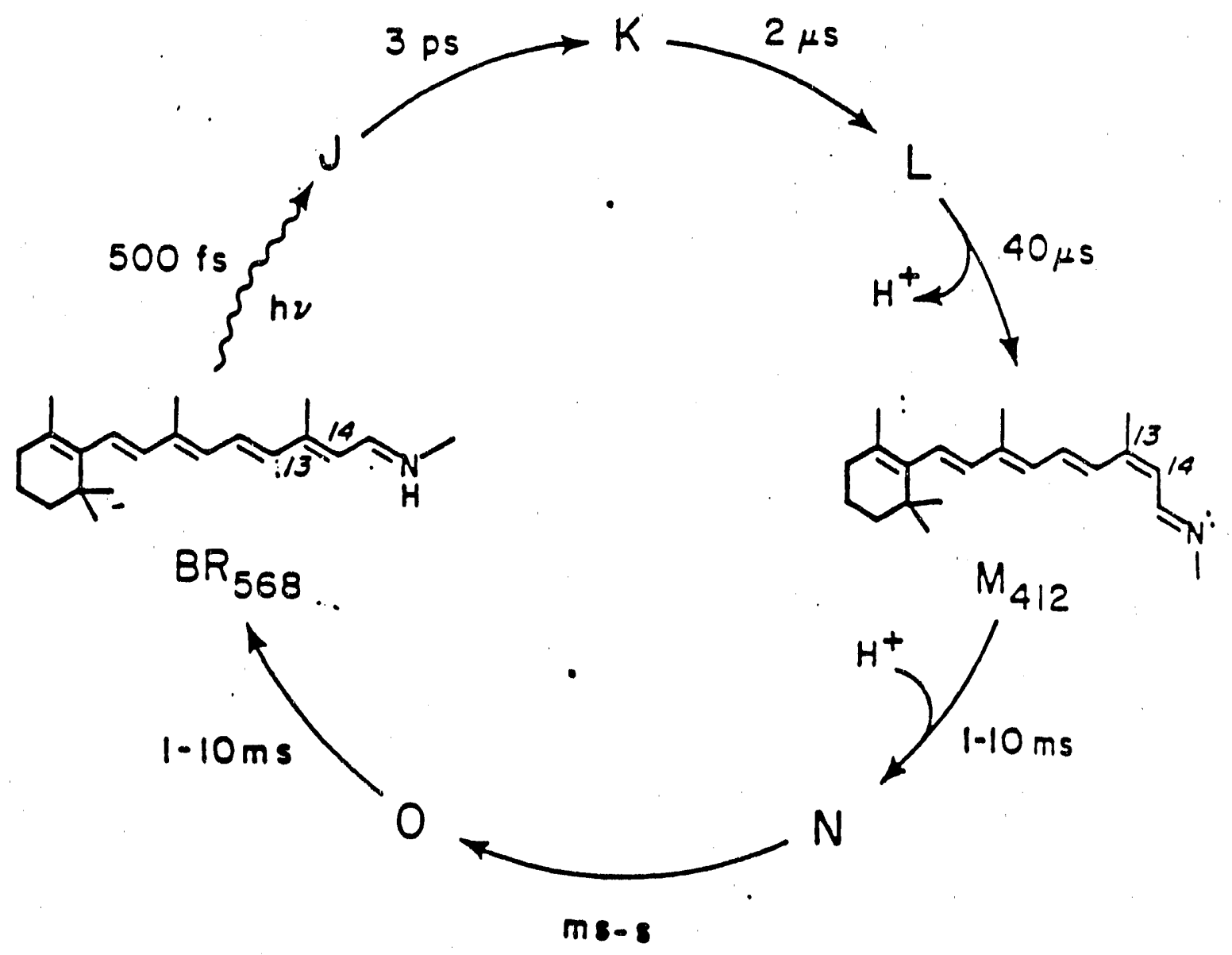

Fig. 2-3 The photocycle of bacteriorhodopsin (Fodor et al. 1988). 
The central question concerning the mechanism of proton translocation is the chemical nature of the transported ion species. Does it involve proton conductance through an extended hydrogenbonded system or is it a gated channel that is activated by light. In a so-called proton-wire model, it has been proposed that the injection of a proton at one end of the chain and the release of a proton from the other end, could be driven by a conformational change of the protein (Morowitz, 1978; Nagle \& Morowitz, 1978). The possibility of a large aqueous channel(10 $\AA$ diam.) or bulk pocket inside the protein was excluded on the basis of data from neutron diffraction (Zaccai \& Gilmore, 1979). $3.5 \AA$ projection structure does not reveal any obvious channel structure (Henderson et al., 1986). But considering the fact that halorhodopsin has a lot of similarities with bacteriorhodopsin and chloride can not be translocated in a similar way as the proton-wire mechanism, the possibility of a small channel, which may not be seen with current structural resolution, is still open. 
2. Halorhodopsin.

a. Biochemical function:

Initially, halorhodopsin was proposed to catalyse light-driven and outward-directed transport of $\mathrm{Na}+$ (Lindley \& Macdonald, 1979; Macdonald et al., 1979). But the protein was identified as an inwarddirected electogenic chloride pump, through studies with membrane vesicle systems (Shobert \& Lanyi, 1982). Its physiological role is speculated to be to maintain osmotic equilibrium with the environment (Lanyi, 1986). Halobacterium halobium cells contain salt in concentration just as high as present in the environment (4-5 $\mathrm{M} \mathrm{NaCl}$ ). The dominant anion is chloride. The large negative-inside potential generated by bR can result in chloride loss from the cells. Halorhodopsin appears to help the ionic balance by inward chloride transport.

b. Structural data.

Halorhodopsin is present in wild-type cells in much smaller quantities than $b R$ and does not appear to be aggregated like $b R$ into discrete membrane patches, although visible $C D$ spectra exhibit an exciton coupling due to trimer aggregates (Sugiyama \& Mukohata, 1984). The single polypeptide chain of $h R$ is composed of 274 amino acids, with a molecular weight 26,961 (Blanck \& Oesterhelt, 1987). The protein has only one lysine at position 242, which must correspond to the retinal-binding site, because resonance Raman spectroscopy has shown that retinal occurs in $h R$ as a protonated Schiff base (Smith et al., 1984; Alshuth et al., 1985). 
A secondary structure model with 7 transmembrane alpha helices was proposed based upon hydropathy and acrophilicity (Fig. 2-4, Blanck \& Oesterhelt, 1987). Proteolytic cleavage data support the proposed structural model by showing that three of six proposed interhelical loops contain proteolytic digestion sites (Shobert et al., 1988). The C-terminal residue can be cleaved from the membraneembedded protein, but not from the protein in right-side-out sealed vesicles. Hence it is concluded that the C-terminal residue faces the cytoplasmic side. There is a net charge differences of three units between the two surfaces ( the C-terminal side has one net positive charge and the $\mathrm{N}$-terminal has two net minus charges,) This might be of significance for the location of the $\mathrm{N}$-terminus on the outside and the C-terminus on the cytoplasmic side. The local potential induced by the charge differences between the surfaces may help to pump chloride inwardly. HR has two cysteines which are located inside the membrane in the model. Indeed $\mathrm{SH}$ groups become accessible to thiol reagents only upon denaturation of the protein.

The comparison of the $b R$ and $h R$ amino acid sequences reveals a conservation of $36 \%$ of amino acid residues in the transmembrane region and $19 \%$ in the aqueous region. Among the transmembrane helices conservation varies by a factor of 2 , with helices $1,2,4$, and 5 being less homologous than helices 3,6 and 7 . Helices 6 and 7 are thought to be involved in the retinal-protein iriteraction. Helices in $h R$ as in bR can be arranged in such a way that an 'inside-out protein' is achieved (Blanck \& Oesterhelt, 1987). Most conserved residues appear to face interhelical spaces. Residues that are conserved include several near the retinal-binding Lys, four Trp and 


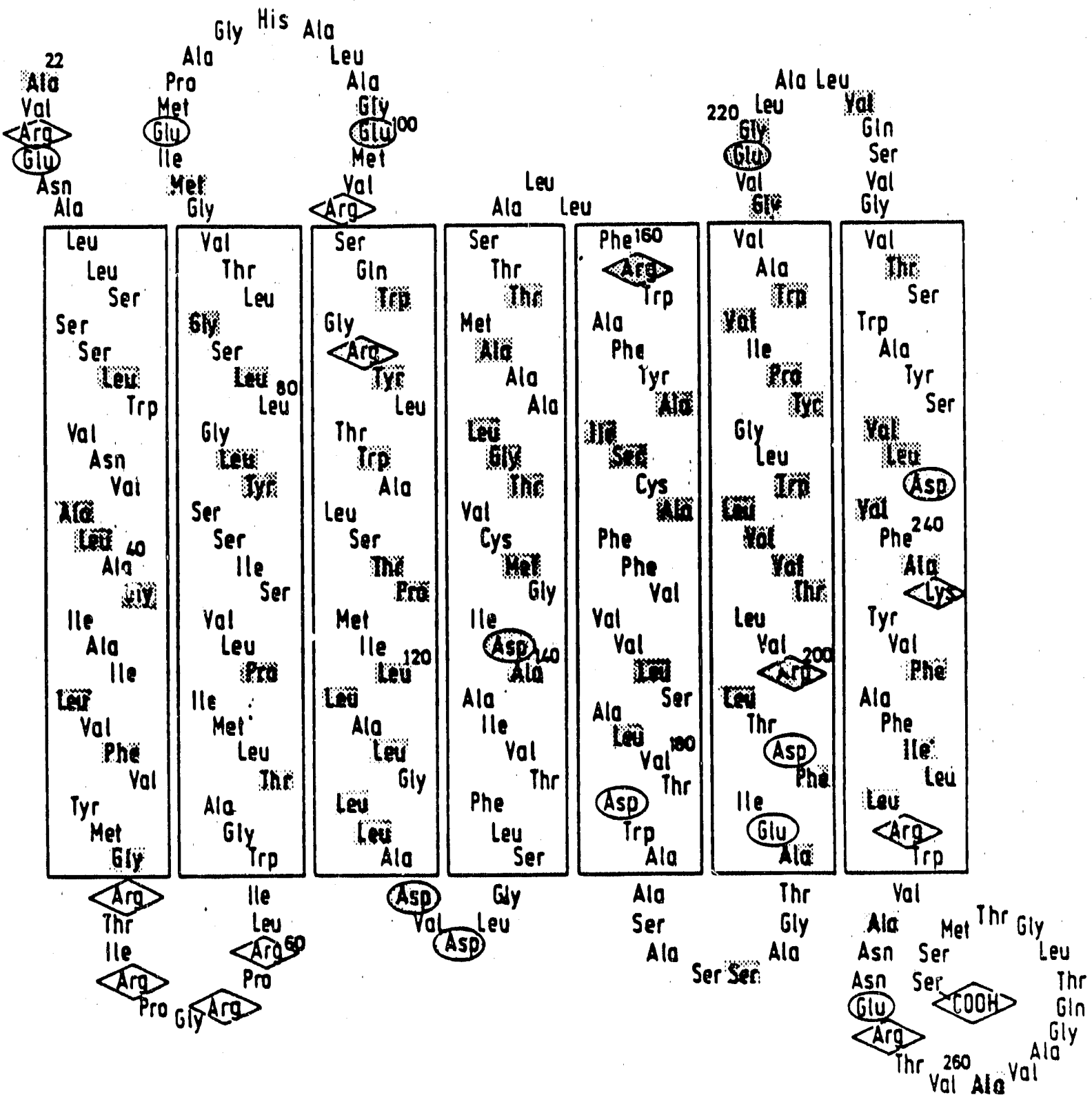

Fig. 2-4. A secondary-structure model for halorhodopsin. Circles and diamonds indicate acidic residues and basic residues respectively. Shaded areas show residues conserved between bR and hR. (Blanck \& Oesterhelt, 1987). 
two interior Asp. Conservation in this area is expected from the resonance Raman spectra that indicate an almost identical structural environment for the retinal moiety of both proteins (Smith et al., 1984; Alshuth et al., 1985).

c. Mechanism of function,

The action spectrum of $\mathrm{hR}$ has a peak around $578 \mathrm{~nm}$, somewhat red-shifted from that of $b R$. The extinction coefficient of the pigment at $578 \mathrm{~nm}$ was determined to be about $50,000 \mathrm{M}-1 \mathrm{~cm}-1$ (Steiner \& Oesterhelt, 1984), somewhat lower than that of bR (63,00C M-1cm-1, Rhehorek \& Heyn, 1979). Resonance Raman spectra of $h R$ show that the retinal is all-trans as in $b R$. The photocycle of hR is illustrated in Fig. 2-5 (Oesterhelt et al., 1985). To understand the photocycle, it is he!pful to know the effect of chloride on the hR spectrum. In the absence of chloride, the absorption peak of $h R$ is blue-shifted to around $565 \mathrm{~nm}$. Also, in the absence of chloride, but at high ionic strength provided by sulfate or other non-halide anions, a different photoproduct which has an absorption peak around 640 $\mathrm{nm}$, is formed. During the photocycle, the primary photoproduct, which absorbs at $600 \mathrm{~nm}$, has a rise time of $5 \mathrm{psec}$, and it decays on a sub- $\mu \mathrm{sec}$ time scale to $h \mathrm{~h}_{520}$. Trans-to 13 cis retinal isomerization takes place with the appearance of $h R_{52} 0$. The photoproducts hR640 and hR565 correspond to photoproducts obtained in the absence of chloride, as described earlier. Hence, it is supposed that chloride is pumped at the transition from hR520 to hR640. Cis to trans isomerization of retinal occurs at the transition to hR565. Upon binding chloride, hR565 converts to 
$h R 578$. At alkaline $p H, h R 410$ appears at the expense of hR565. $H_{4} 10$ represents the deprotonated Schiff base. Once produced, hR410 relaxes very slowly (over $1 \mathrm{hr}$ ) and can easily accumulate.

A current model for chloride translocation is as follows (Lanyi, 1984). There is a series of chloride-binding sites in the protein (possibly four Arg residues inside the membrane; Arg 108, 161, 200, 251, Fig. 2-4). Isomerization of the retinal and the accompanying movement of the protonated Schiff base alters the distribution of positive charges in such a way that chloride. migrates through the series of binding sites. Release of the chloride on the cytoplasmic site occurs when the retinal reisomerizos and the transient binding site loses affinity to the chloride. 


\section{all-trans retinal}

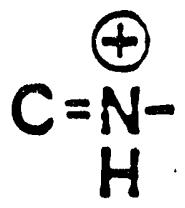

\section{a-trans} retinal

13-cis retinal

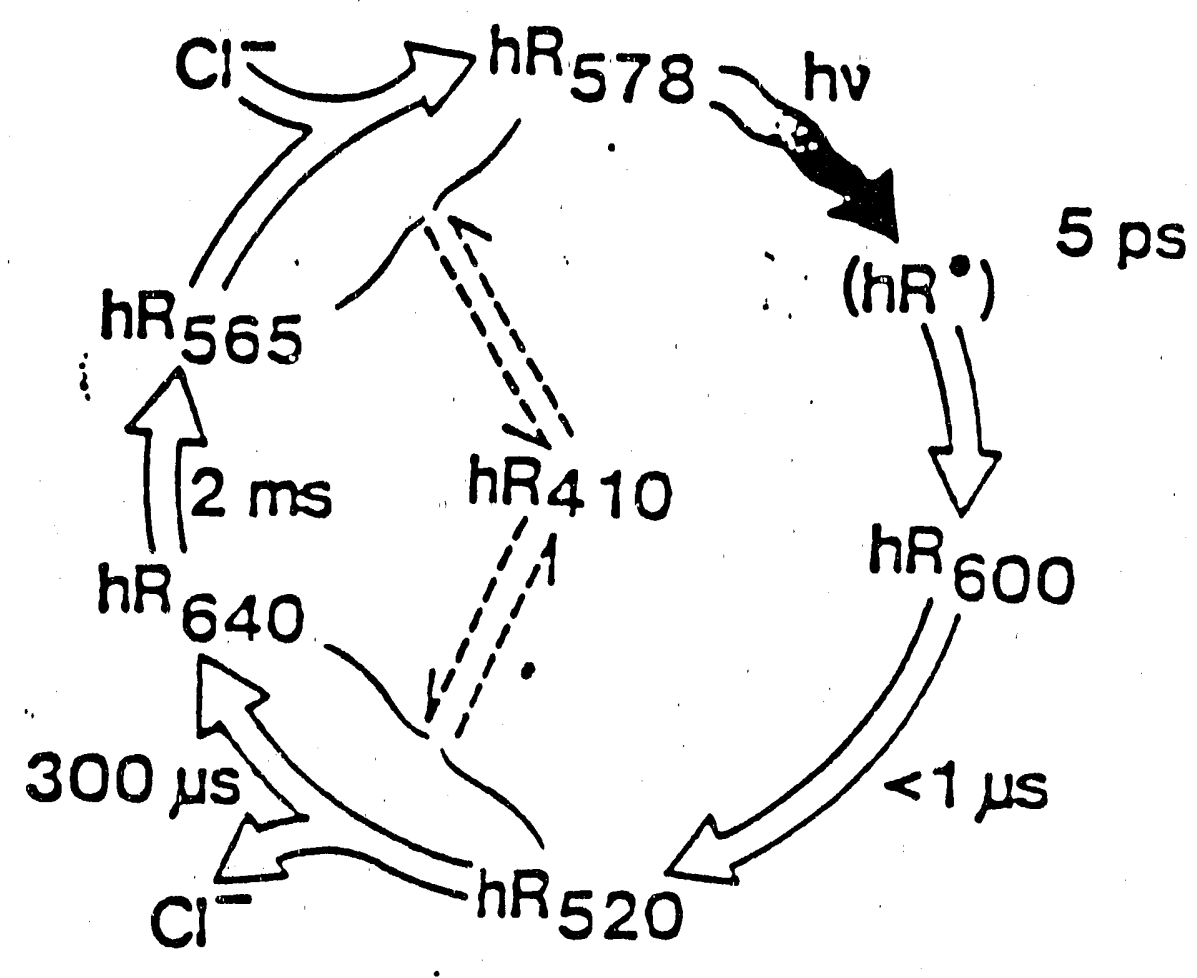

13 -cis retinal

Fig. 2-5. The photocycle of halorhodopsin(Oesterhelt et al., 1985). 
B. Aim of this dissertation.

Since the discovery of bacteriorhodopsin(bR) as the lightdriven proton pump in Halobacterium halobium, a lot of biochemical and structural studies have been done on bacteriorhodopsin in the past two decades. But still many important questions about bacteriorhodopsin have not been settled. The central question concerns the mechanism of proton translocation. Does it involve proton conductance through an extended hydrogen bonded system (socalled protein-wire mechanism) or is it a gated channel that is activated by light. A three-dimensional high resolution structure which gives all the locations of the amino acids in the threedimensional structure, could possibly settle the question. But such high resolution structural information is not available yet.

Halorhodopsin(hR) is a light-driven chloride pump. Halorhodopsin appears to have a lot of similarities with bacteriorhodopsin in the primary sequence (Blanck \& Oesterhelt, 1987), the structural environment for the retinal moiety (Smith et al., 1984) and the secondary structure (Jap \& Kong. 1986). Hence, the comparison of the structures of bacteriorhodopsin and halorhodopsin can give an interesting clue to the mechanism of proton translocation. Chloride can not be translocated in a similar way as the proton-wire mechanism. If there is a close similarity between the structures of $b R$ and $h R$, this may indicate a similarity of the mechanism of pumping. It would then be much more likely that there is a channel in $b R$, through which protons are translocated. 
In this thesis research, crystallizatior: of halorhodopsin has been attempted through the reconstitution of purified protein with the purple membrane lipids. Also the UV circular dichroism spectrum of the purified protein has been measured to get information about the secondary structure of the protein. The first important step for crystallization is to get an homogeneous protein which is pure and not denatured. Here homogeneous halorhodopsin has been obtained by the modification of existing purification methods. Some nice looking membrane patches, which have the same density as purple membrane, have been obtained. But. unfortunately, they are not crystalline. Hence, no structural information of hR could be obtained from electron microscopy. The procedure of $h R$ reconstitution is described in detail, and some other strategies of ciystallization which were not pursued because of the limited time in graduate study, are discussed in this dissertation. 
1.1. Purification of halorhodopsin.

A. Introduction.

The first important step for crystallization is to get an homogeneous protein which is pure and not denatured. Halorhodopsin can be purified by a number of methods ( Taylor, M. E. et al., 1983; Steiner, M. \& Oesterhelt, D., 1983: Ogurush, T. et al., 1984; Sugiyama, Y. \& Mukohata, Y., 1984 ). The main difference between the methods is the detergent used for solubilization: Lubrol PX (Steiner, M. \& Oesterhelt, D., 1983), C12Eg (Sugiyama, Y. \& Mukohata, Y., 1984 ) and Triton X-100 (Ogurush, $T$. et al., 1984) are effective but difficult to remove; octylglucoside (Taylor, M. E. et al., 1983) is expensive but easy to dialyze out. In general, the purity of the protein can be checked by the absence of extraneous bands on SDS gels. In the case of $h R$, another good criterion for purity is the ratio of absorption maxima at $280 \mathrm{~nm}$ and $578 \mathrm{~nm}$ (A280/A578). Since hR has a peak of absorbance around $578 \mathrm{~nm}$ due to the bound retinal and other contaminating proteins do not have absorbance around $578 \mathrm{~nm}$, in the course of purification, $A_{2} 80 / A_{578}$ keeps decreasing and reaches a final value at the end of purification. $A_{2} 80 / A_{578}$ is also a good criterion for the intactness of $h R$. If some fraction of the protein loses its chromuphore during the purification, A280/A578 will go up. Sugiyama, Y. \& Mukohata, Y. (1984) have reported the

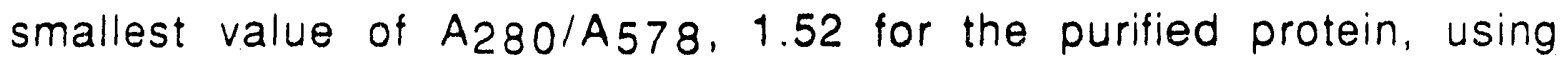
$\mathrm{C}_{12} \mathrm{Eg}_{9}$. Also, $\mathrm{hR}$ purified in the presence of $\mathrm{C}_{12} \mathrm{E}_{9}$ initially appears to be a trimer, judging from the molecular weight estimated though molecular sieve chromatography and from the exciton splitting in 
the visible circular dichroism spectrum (Sugiyama \& Mukohata,1984). The trimer conformation of purified hR might be helpful for the crystallization of the protein, considering the fact that the $b R$ trimer forms a unit cell in the purple membrane, although $b R$ exists as monomer in the orthorhornbic two-dimensional crystal (Michel et al, 1980). Hence, in this dissertation work, $\mathrm{C}_{12} \mathrm{E}_{9}$ was used for the purification of hR.

A lot of problems were encountered when Sugiyama \& Mukohata's purification procedure was first tried. So major modifications have been made in the purification procedure; replacing Tween-20 washing with $\mathrm{C}_{12} \mathrm{Eg}_{9}$ washing, and crianging running conditions and order for chromatography (running hydrophobic chromatography before hydroxylapatite chromatography). The purification procedure used in this dissertation work consists of four steps; washing of the membrane with $\mathrm{C}_{12} \mathrm{E}_{9}$, detergent solubilization, phenylsepharose chromatography and hydroxylapatite chromatography. All operations were carried out at $4{ }^{\circ} \mathrm{C}$.

B. Materials and Methods

Materials.

Phenyl-sepharose CL-4B, C12Eg (Polyoxyethylene 9 Lauryl Ether or Polydocanol), MOPS(3-morpholinopropane-sulfonic acid), bicinchoninic acid prctein assay kit and DNAase were purchased from Sigma, while hydroxylapatite (DNA grade) and G-250 protein assay kit 'vere purchased from Bio-Rad. 
Preparation of $\mathrm{C}_{i 2} \mathrm{E}_{9}$-washed membrane.

Halobacterium halobium JW-12 was grown in an 80-liter culture and harvested, according to the procedure described by Oesterhelt \& Stoecknius (1974). Typically, from 100 to $150 \mathrm{~g}$ of cells were obtained after 7 days from an 80- liter culture. After washing with $4 \mathrm{M} \mathrm{NaCl}$, the cells were suspended in $200 \mathrm{ml}$ of $4 \mathrm{M} \mathrm{NaCl}$ and lysed by dialysis in the presence of $10 \mathrm{mg}$ of DNAase at $4{ }^{\circ} \mathrm{C}$ for $18 \mathrm{hr}$ against 6 liters of $10 \mathrm{mM}$ MOPS pH 7.0 buffer. The iysate was cleared of large debris by centrifugation (2,000 $\mathrm{g} 15 \mathrm{~min})$ and the cell membranes were then sedimented $(150,000 \mathrm{~g}, 2 \mathrm{hr})$. The membrane $(2.4 \mathrm{~g}$ of protein) was washed in $400 \mathrm{ml}$ of $4 \mathrm{M} \mathrm{NaCl}$ and then incubated with $400 \mathrm{ml}$ of $2 \mathrm{M} \mathrm{NaCl}, 0.5 \% \quad \mathrm{C}_{12} \mathrm{Eg}$ and $10 \mathrm{mM}$ MOPS $\mathrm{pH} 7.0$ buffer for $30 \mathrm{~min}$ at $4{ }^{\circ} \mathrm{C}$. The incubated membrane was then centrifuged $(150,000 \mathrm{~g}, 2 \mathrm{hr})$. After centrifugation, the membrane pellet consisted of two layers. The bottom layer had a yellowish color and did not seem to have any $h R$, so only the top layer was kept for the next step. Washing of the membrane with $\mathrm{C}_{12} \mathrm{Eg}_{9}$ was repeated about six more times with $200 \mathrm{ml}$ of the buffer. If the supernatant after centrifugation shows purple color indicating the presence of hR, washing should be stopped. The supernatants during the course of washing have a strong absorbance peak at $410 \mathrm{~nm}$ indicating the presence of cytochromes. As the $\mathrm{C}_{12} \mathrm{Eg}$ washing step was repeated, the colour of the membrane pellet increasingly becomes a brighter purple color. 
Detergent-Solubilization of the membrane.

$\mathrm{C}_{12}$ Eg-washed membrane was incubated with $100 \mathrm{ml}$ of $2 \mathrm{M}$ $\mathrm{NaCl}, 1 \% \mathrm{C}_{12} \mathrm{Eg}$ and 10mM MOPS pH 7.0 buffer for $12 \mathrm{hr}$ at $40 \mathrm{C}$. Centrifugation for $2 \mathrm{hr}$ at $150,000 \mathrm{~g}$ separated a purple-colored supernatant from a yellow-white pellet. The supernatant solution was concentrated to $50 \mathrm{ml}$ by ultrafiltration (Amicon YM 100).

\section{Phenyl-sepharose chromatography.}

Solubilized proteins were loaded onto a phenyl-sepharose column $(25 \mathrm{~mm} \times 30 \mathrm{~cm})$ which had been equilibrated with 1 liter of $4 \mathrm{M} \mathrm{NaCl}, 0.5 \% \mathrm{C} 12 \mathrm{Eg}$ and $10 \mathrm{mM}$ MOPS pH 7.0 buffer (buffer $A$ ). As the column got equilibrated, the appearance of the phenyl-sepharose gel turned turbid with the binding of detergent $\mathrm{C}_{12} \mathrm{Eg}_{9}$. The optical change progressed from the top part of the column down to the bottom of the column. When it reached the bottom of the column, equilibration was immediately stopped. The column should not be over equilibrated. Proper equilibration of the column is critical for the performance of the phenyl-sepharose chromatography. But, if the column is not equilibrated enough, then hR gets strongly bound to the gel and will not be eluted easily. Proteins were eluted at a flow rate of $15 \mathrm{ml} / \mathrm{hr}$ with the same buffer. Under normal conditions, the purple colored material was not significantly retained by the column and spontaneously eluted. Brown colored material with an absorption peak at $410 \mathrm{~nm}$ eluted in the later fractions. Fractions with A280/A578 below 2.5 were pooled. The phenyl-sepharose column was regenerated by washing with 2 times the column volume of butanol followed by washing with one column volume of $50 \%$ 
ethanol and 50\% water mixture. Then the column was thoroughly washed with water and kept ready for later use. After washing with butanol, the phenyl-sepharose turned transparent again.

Hydroxylapatite chromatography (HA).

Pooled fractions from the phenyl-sepharose chromatography were concentrated to $20 \mathrm{ml}$ and loaded onto a hydroxylapatite column $\left(1.6 \mathrm{~cm} \times 6 \mathrm{~cm}\right.$ ) equilibrated with $4 \mathrm{M} \mathrm{NaCl}, 0.5 \% \mathrm{C}_{12} \mathrm{Eg}$ and $10 \mathrm{mM}$ MOPS pH 7.0 buffer. The purple colored material was not absorbed and eluted with the void volume. Usually, after the hydroxylapatite chromatography step, the preparation was pure hR. When the preparation was not pure after the HA column step, judging from the SDS gel electrophoresis or the presence of an absorbance peak at $410 \mathrm{~nm}$, phenyl-sepharose chromatography was done one more time.

Analytical methods.

The amount of retinal pigments were determined by difference spectra before and after bleaching the pigment with $0.1 \mathrm{M}$ hydroxylamine at $20{ }^{\circ} \mathrm{C}$ for $16 \mathrm{hr}$ in the presence of $1 \% \mathrm{C}_{12} \mathrm{Eg}$. The difference spectrum was recorded on a Beckman DU-40 spectrophotometer, and an extinction coefficient of $50,000 \mathrm{M} / \mathrm{cm}$ was used for calculation of the pigment concentration (Steiner \& Oesterhelt, 1983). Protein was determined according to Smith, P. K. et al. (1985) using bR as a reference. Proteins reduce alkaline $\mathrm{Cu}(I I)$ to $\mathrm{Cu}(\mathrm{I})$ in a concentration dependent manner. Bicinchonic acid is a highly specific chromogenic reagent for $\mathrm{Cu}(\mathrm{I})$ forming a purple 
complex with an absorbance maximum at $562 \mathrm{~nm}$. The resultant absorbance at $562 \mathrm{~nm}$ is directly proportional to protein concentration. Smith's method is tolerant of many detergents including SDS unlike the methods using the spectral shift of dye upon binding to hydrophobic materials. Protein in the membrane fraction was measured after being solubilized in $2 \%$ SDS. Purity of the protein sample was checked by SDS-polyacrylamide gel electrophoresis. Aliquots of protein sample were dialyzed against distilled water for the gel electrophoresis. Then the dialyzed protein sample was incubated in $0.1 \mathrm{M}$ phosphate $(\mathrm{pH} 7.0) 0.5 \%$ SDS and $1 \%$ B-mercaptoethanol at room temperature for at least an hour. $12 \%$ SDS-polyacrylamide gel was used. An important observation in running gel electrophoresis is that if the protein sample was boiled as commonly done for other membrane proteins, then halorhodopsin formed aggregates and did not enter the running gel at all. 
C. Summary for the purification of $h R$.

Table 3-1.

Stage of purification

Protein Pigment Purification Yield $(\mathrm{mg})$ (nmol) factor $\%$

Membranes

2,400

1,200

1

100

$C_{12} E_{9}$-washed membrane

180

980

11

82

Solubilized proteins

63

960

31

80

Phenyl-sepharose

9

530

54

44

Hydroxylapatite

12

480

80

The value for a purification from 80 । cell culture is given. The final yield of $h R$ is $67 \%$ on the assumption that $40 \%$ of the initial pigment in the membrane is due to $\mathrm{sR}$. 
D. Results and Discussion.

Preparation of $\mathrm{C}_{12} \mathrm{Eg}$-washed membrane.

In this work, $C_{12}$ Eg-washing removed more than $90 \%$ of the proteins from the membrane with about $20 \%$ loss of retinal pigments. $\mathrm{C}_{12} \mathrm{Eg}_{9}$-washing is much more effective than the Tween20 washing used in Steiner \& Oesterhelt (1983) and Sugiyama \& Mukohata (1984), where it was reported that $40 \%$ of retinal pigments were lost after the Tween-20 washing. The effectiveness of washing of the Halobacterium halobium membrane with $\mathrm{C}_{12} \mathrm{Eg}$ was found accidentally. When the amount of $\mathrm{C}_{12} \mathrm{Eg}_{9}$ applied to the membrane for solubilization was not enough, hR was not solubilized, although other proteins were extracted. Hence extraction of proteins from the membrane was tried in a more controlled way, with almost no loss of retinal pigments, as described above in the method section. The effectiveness of $\mathrm{C}_{12} \mathrm{Eg}$-washing varied for different preparations. This step is a critical one for the purification of $h R$. When the initial preparation was not very clean, the hydrophobic chromatography step had to be done at least twice and so the final yield dropped significantly.

Detergent solubilization of the membrane.

According to Sugiyama \& Mukohata (1984), both $h R$ and $s R$ are solubilized in a stable form from the membrane with $\mathrm{C}_{12} \mathrm{Eg}$, although SR can be removed during the chromatography step. HR solubilized in $C_{12} E_{9}$, appears to be an oligomer, judging from the $C D$ exciton coupling, and an apparent molecular weight of above 100,000 
through a TSK-G3000SW sizing column (Sugiyama \& Mukohata 1984). On the other hand, the micellar weight of $\mathrm{C}_{12} \mathrm{Eg}_{9}$ itself turned out to be between 50,000 and 100,000 . The concentration of $C_{12} E_{9}$ in buffer $A$ which contains $0.5 \% \quad C_{12} E_{9}$ stayed the same after buffer $A$ weint through the Amicon YM 100 filter, but went up significantly after the Amicon YM 50 filter step (The concentration of $\mathrm{C}_{12} \mathrm{Eg}$ was measured using coomassie blue G-250 Bio-Rad protein assay method according to Rosenthal \& Koussale, 1983.). Furthermore, trimeric hR will not pass through the YM 100 filter, while monomeric hR, will. Hence, hR solubilized in $\mathrm{C}_{12} \mathrm{Eg}$ can be concentrated through the Amicon YM 100, without concentrating the detergent.

Purification of hR.

Table 1. summarizes the individual steps leading to pure hR which migrates as a single band on a SDS gel, with $67 \%$ yield. This data represents for the best preparation. As mentioned earlier in the discussion of the $\mathrm{C}_{12} \mathrm{Eg}$-washing step, the final yield decreased significantly if the initial preparation was not very clean. Also the selection of a good colony from the petri dish for the initial inoculation turned out to be important. For some cultures, the amount of $h R$ in the initial membranes was slightly less than half of that listed in Table 1. Dr. Bing Jap helped me to find good colonies which appeared to have a little bit more purple color. All the colonies do not have much color, with only a slight tint of purple color. Hence it was not easy to discriminate the color of colonies. Fig. $3-1,3-2$ and $3-3$ are the absorption spectra of the initially solubilized protein sample, the sample after the phenyl-sepharose 
chromatography step and the final pure halorhodopsin respectively. Those figures show that after each column step, the absorbance peak at 410 and the $A_{280} / A_{578}$ ratio decrease. The absorption maximum in the visible region was at $578 \mathrm{~nm}$ and the $A_{280} / A_{578}$ ratio for pure hR was 1.48, which was even smaller than the value 1.52 reported in Sugiyama \& Mukohata (1984). It was found that when the absorption spectrum of the sample showed no absorption peak at $410 \mathrm{~nm}$ and the A280/A578 ratio was better than 1.55, no contamination could be detected from SDS gel electrophoresis. Hence the absorption spectrum can be used as one criterion for purity of halorhodopsin .

Halorhodopsin solubilized in $\mathrm{C}_{12} \mathrm{Eg}$ appeared to be pretty stable for at least a week, during which purification can be done. The protein trimer started being dissociated into monomers, seven to ten days after the solubilization and then the $A_{280} / A_{578}$ ratio also started dropping down, indicating the loss of its chromophore. Hence, it is important to use freshly purified protein for any further experiments. 


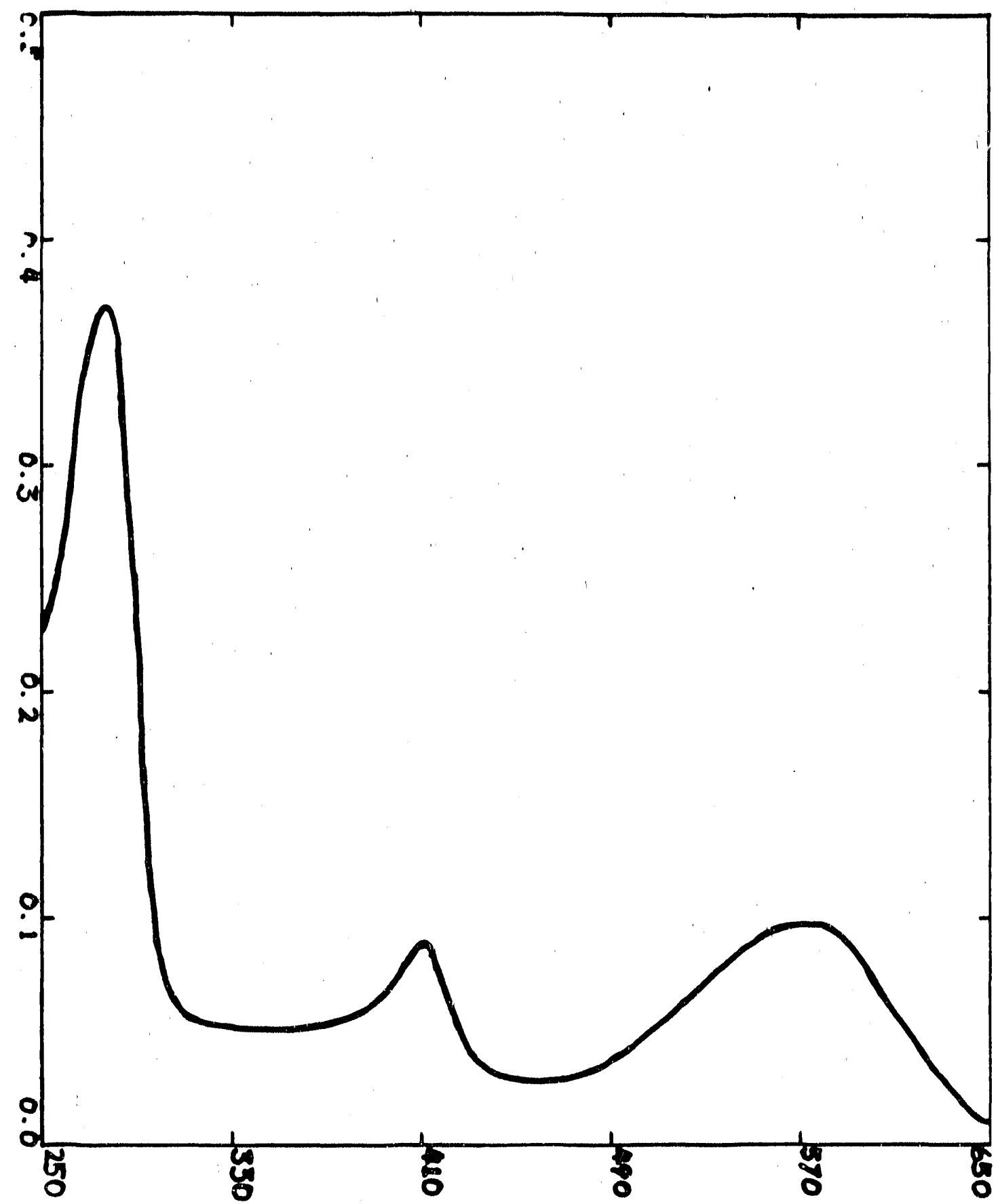

Fig. 3-1 The absorption spectrum of the initially solubilized protein sample. 


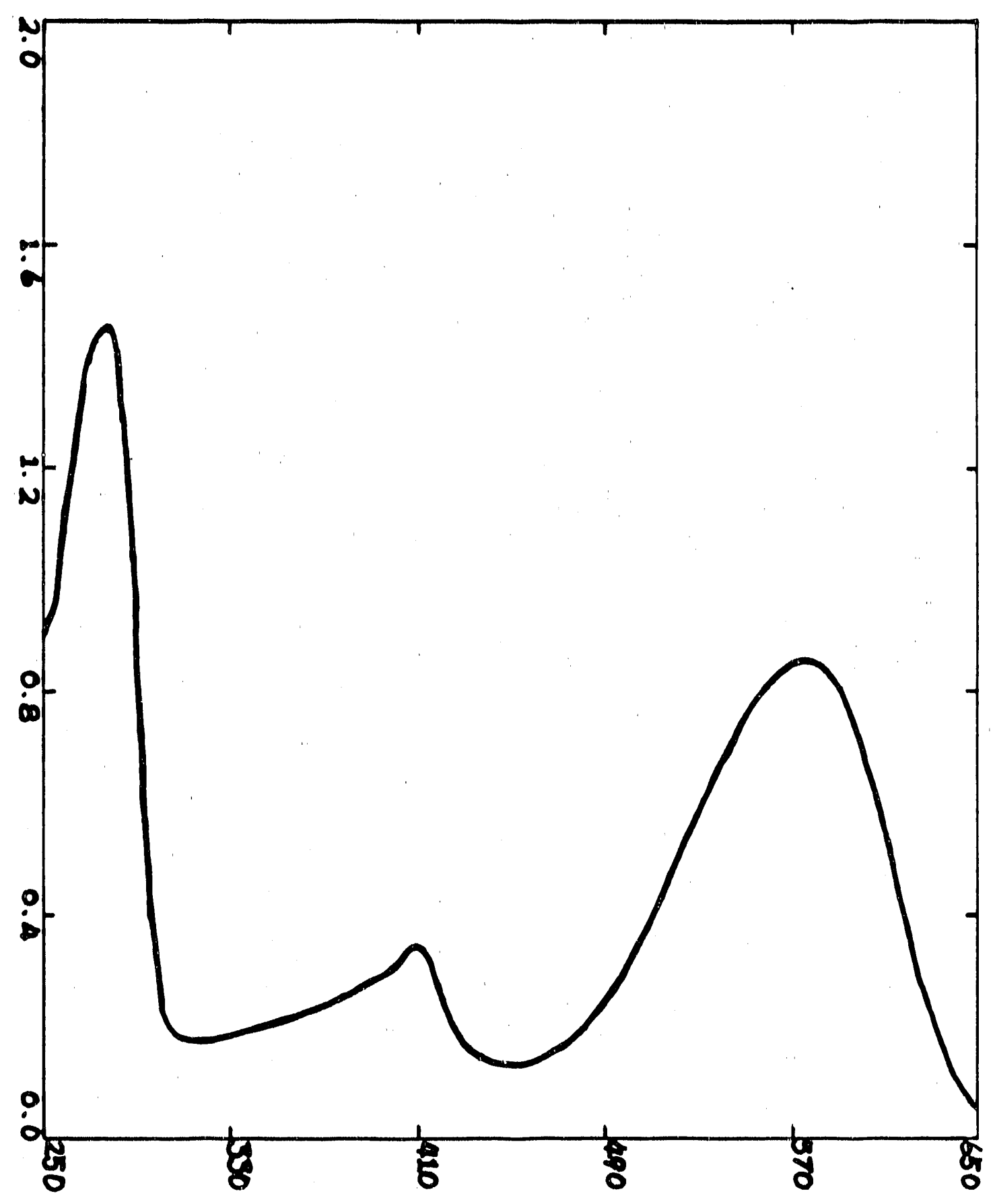

兽

Fig. 3-2 The absorption spectrum of the protein sample after phenyl-sepharose chromatography step. 


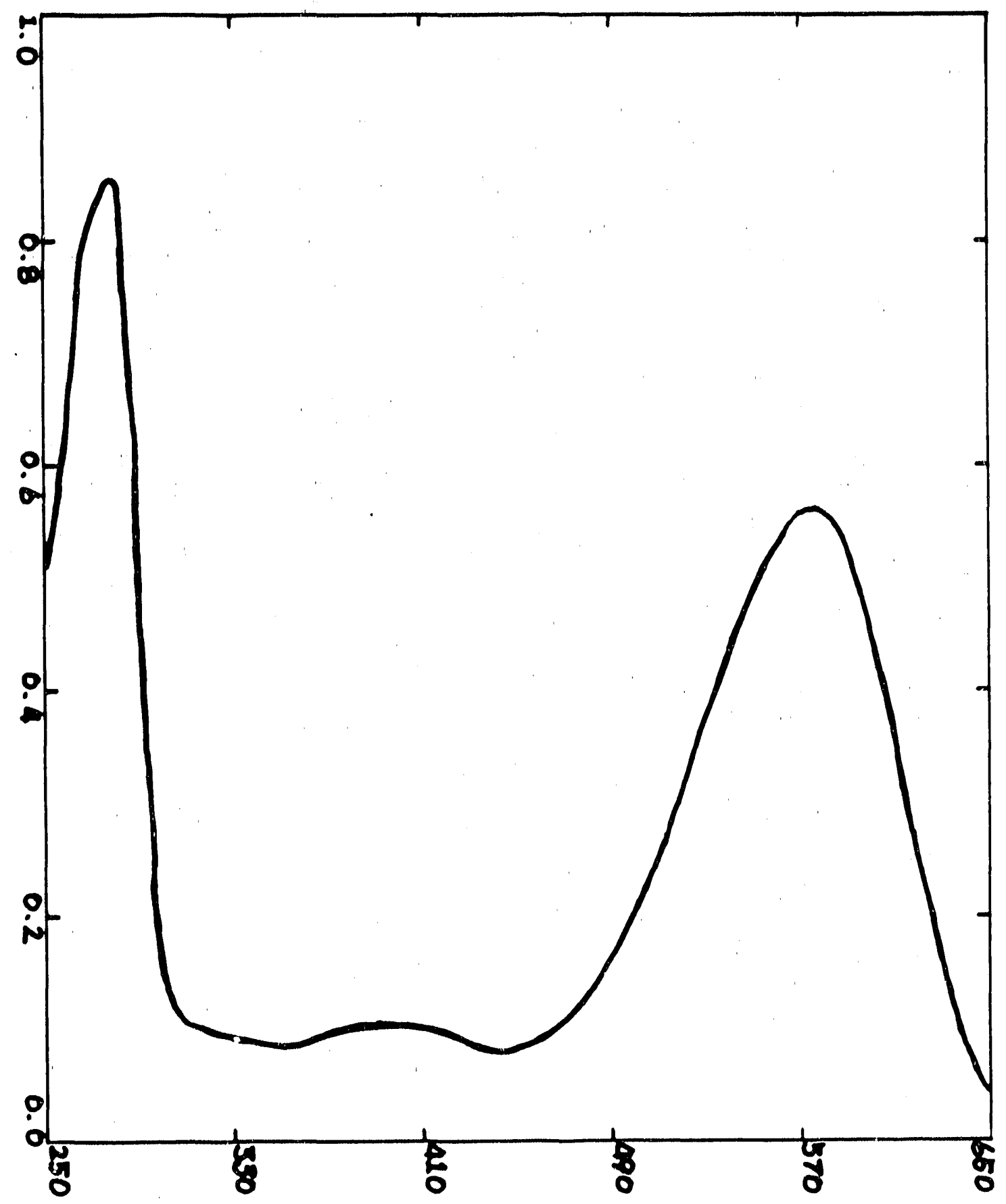

Fig. 3.3 The absorption spectrum of pure halorhodopsin. 
IV. Circular Dichroism study of halorhodopsin.

A. Introduction.

Circular Dichroism has been used to estimate the secondary structure of a protein, since the late 1960's (Adler et al. 1969). The approach is largely empirical and based upon the CD spectra of the polypeptide backbone $(190-250 \mathrm{~nm})$ for model polypeptides. It is assumed that the alpha-helix, B-sheet and random coils each have a single characteristic $C D$ spectrum, and the $C D$ spectrum of a protein can be represented as a linear combination of the contributions from each secondary structure form. At any fixed wavelength, the $C D$ spectrum of a protein is given as the form, where $X$ is the ellipiticity,

$$
X=f_{h} X_{h}+f_{\beta} X_{\beta}+f_{r} X_{r}
$$

and then $f h, f \beta$ and $f_{r}$ are varied so as to obtain a best fit to the experimental curve over the entire wavelength.

Ultraviolet circular dichroism (CD) spectra in the interval from 190 to $240 \mathrm{~nm}$ have been measured for halorhodopsin and bacteriorhodopsin to compare their secondary structure. The results indicate that $h R$ and $b R$ have nearly identical secondary structure.

B. Materials and Methods.

This part of the experiments was done in the early stage of my graduate work. For the CD spectroscopy study, halorhodopsin was purified using octyl D-B-glucopyranoside (OG) according to the procedure described by Taylor et al. (1983). Fractions with no visible impurity as observed on SDS gel electrophoresis, were 
collected and dialyzed in the dark against several changes of $3 \mathrm{M}$ $\mathrm{NaCl}$ and $50 \mathrm{mM}$ HEPES $\mathrm{pH} 7.0$ buffer at $4{ }^{\circ} \mathrm{C}$. After removal of $O G$ (Calbiochem) by dialysis, hR was dialyzed at $40 \mathrm{C}$ in the dark against two changes of $20 \mathrm{mM}$ Na-phosphate $\mathrm{pH} 7.0$ buffer. Some hR was resolubilized for $6 \mathrm{hrs}$ in $15 \mathrm{mM} \mathrm{OG}$ and $20 \mathrm{mM} \mathrm{Na-phosphate} \mathrm{pH} 7.0$ buffer and then immediately used for spectral studies.

Five milligrams of purple membrane were resuspended in 20 $\mathrm{ml}$ of $1.3 \% \mathrm{OG}$ and $20 \mathrm{mM} \mathrm{Na}$-phosphate $\mathrm{pH} 6.9$ buffer. The suspension was kept in the dark at room temperature for $30 \mathrm{hrs}$ and then centrifuged at $150,000 \mathrm{~g}$ for $30 \mathrm{~min}$ to get rid of any unsolubilized material.

Circular dichroism was measured by Dr. Bing Jap with a Jasco J-500A spectropolarimeter. The dichrograph was calibrated with a standard solution of d-10-camphorsulfonic acid. The spectrum of each given $h R$ or $b R$ sample was obtained from an average of at least two scans.

The concentrations of $h R$ and $b R$ used in the $C D$ experiments were determined by direct amino acid analysis. The concentration of $b R$ in $O G$ was also determined from the absorbance at $280 \mathrm{~nm}$. The extinction coefficient under these conditions was assumed to be 63,000 (Rehorek \& Heyn, 1979). The agreement of the concentration of $b R$ in $O G$ determined by the above two different methods was within $5 \%$.

The CD spectra, after conversion to molar ellipticity were fitted by a linear combination of three different basis functions for alpha-helix, B-sheet and random coils, as described by Chen, $Y$, et al. (1974). Since $X$-ray, diffraction and electron microscopy indicates 
that the helical strands in bR span across a membrane of $45 \AA$ thickness, the basis function appropriate for alpha-helix that is 25 residues long was used.

C. Results and Discussion.

$C D$ spectra of $h R$, with or without $O G$ are shown in Fig. 4-1. The spectrum in $O G$ is expected to have the advantage of being free from light scattering and absorption-flattening artifacts. Least-squares curve fitting of the spectra, with the basis functions of Chen, $Y$. et al. (1974) gives an alpha-helix content of $51 \%$ and B-sheet of $28 \%$ for $h R$ solubilized in $O G$. The theoretical curves obtained from the least-squares fitting are in an acceptable agreement with the experimental data (Fig. 4-1).

The $C D$ spectra of $b R$ and $h R$ solubilized in $O G$ are shown in Fig. 4-2. The spectra are very similar in magnitude and in their detailed shapes, suggesting that $h R$ and $b R$ have very similar secondary structure contents. Least-squares curve fitting of the $C D$ spectrum of $b R$ in OG yields an alpha-helical content of $54 \%$ and B-sheet content of $27 \%$. These percentage values are in a good agreement with those reported in Triton X-100 (Jap et al., 1983). The CD spectrum of bR solubilized in $O G$ has been reported previously by Mao \& Wallace (1984). The ellipticity at $222 \mathrm{~nm}$ of $\mathrm{bR}$ in $O G$ measured here has a magnitude above 1.2 times larger than the value reported by Mao \& Wallace (1984), and the ratio of the magnitudes at 193 to $222 \mathrm{~nm}$ is about 2.2, which is significantly larger than that derived 
from the spectra of Mao \& Wallace (1984). This discrepancy may be due in part to an error in the value of protein concentration used by the authors. The smaller ratio of the ellipticity at 193 and $222 \mathrm{~nm}$ of their spectra could be explained by some degree of aggregation of their sample.

Caution should always be used in quantitative estimation of protein secondary structure on the basis of the CD spectra. Although, estimation of helical content of proteins, particularly those having high helical contents, can be pretty accurate (Chen, Y. et al. 1974), estimation of $B$-sheet is rather unreliable because of the variations of B-sheet structures. 


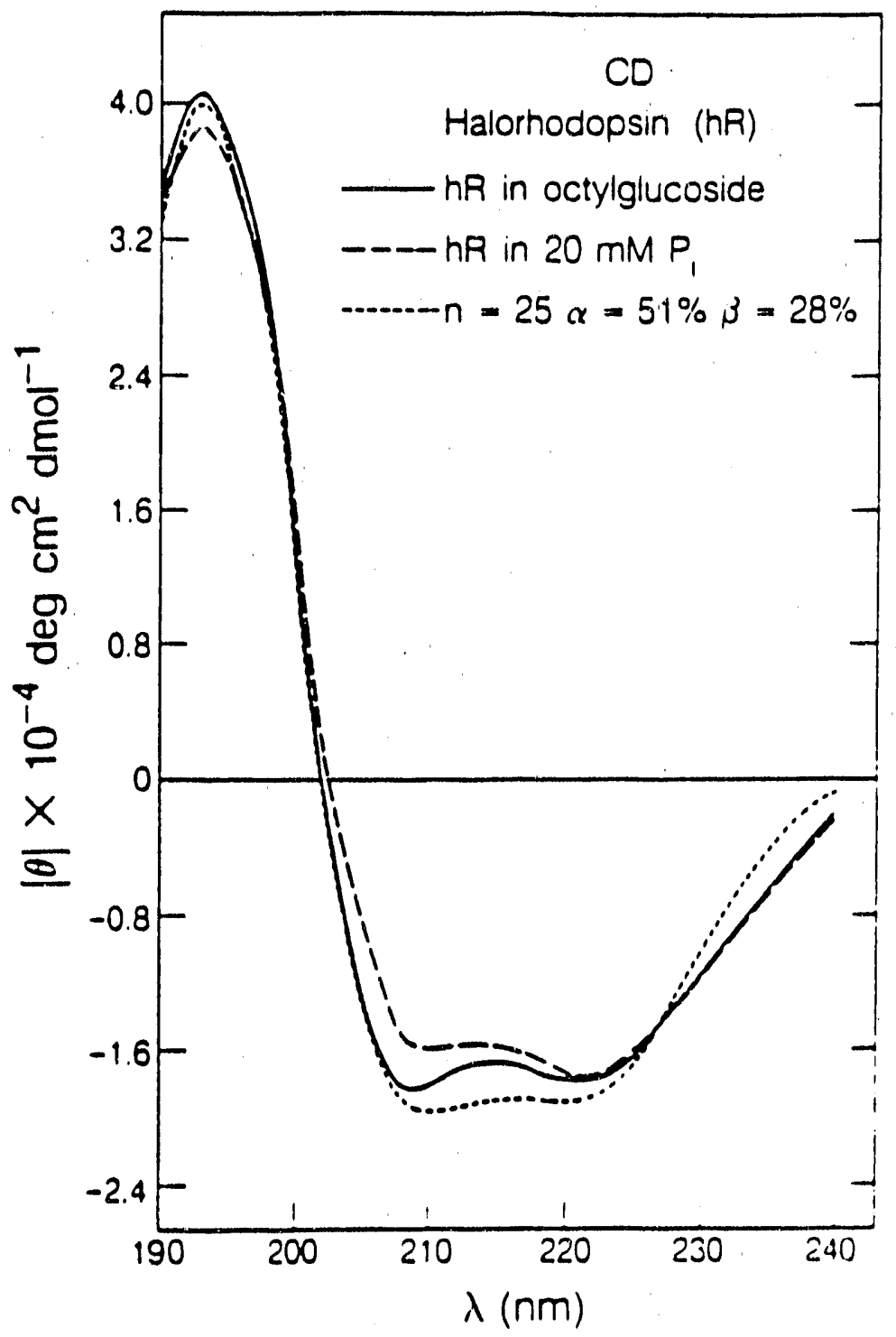

Fig. 4-1 The $C D$ spectra of $h R$ in $20 \mathrm{mM}$ phosphate buffer $(\mathrm{pH} 7)$, with and without $15 \mathrm{mM}$ octyl glucoside. 


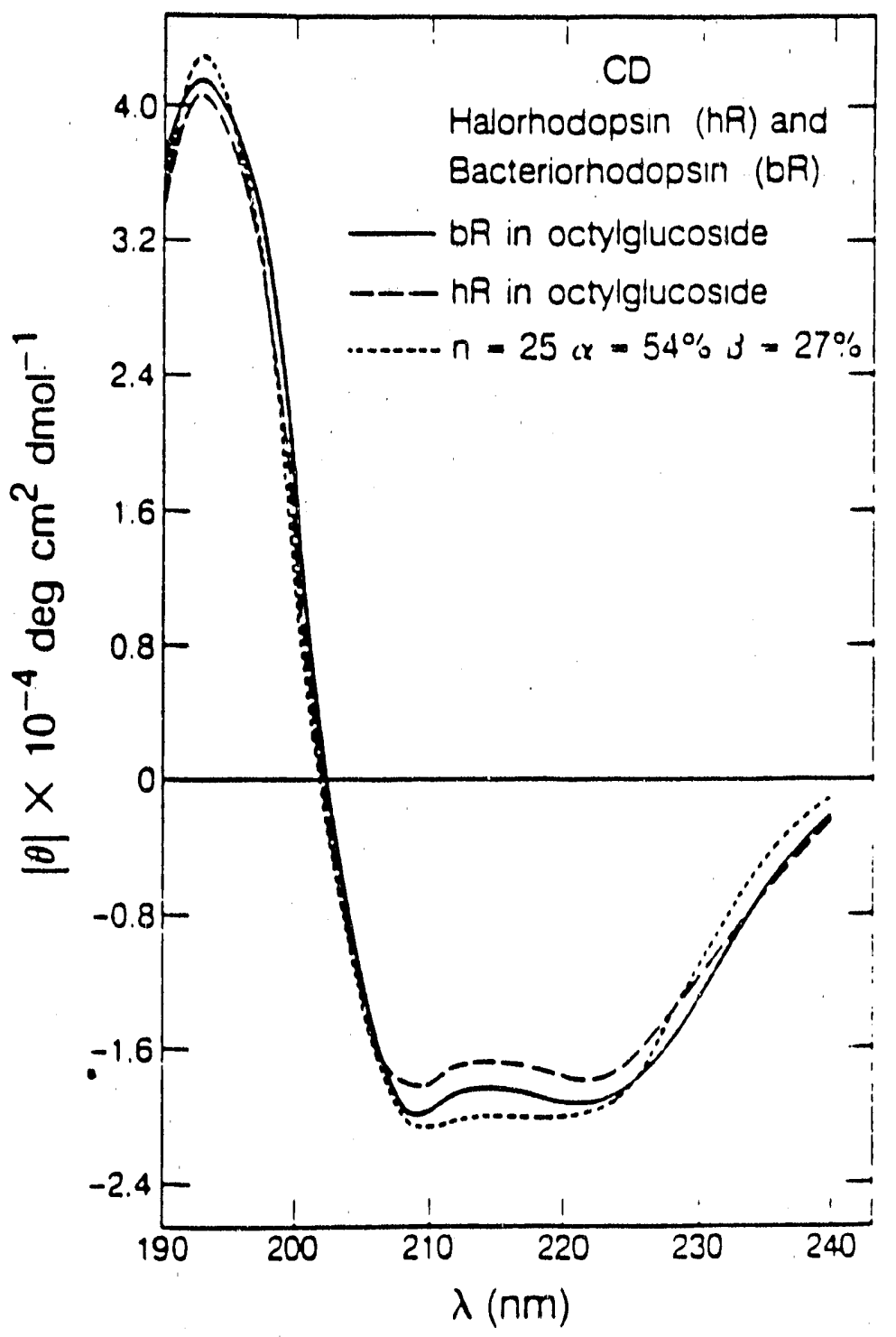

Fig. 4-2 The CD spectra of $h R$ and $b R$ solubilized in octyl glucoside. 
V. Reconstitution of halorhodopsin.

A. Introduction.

Biological cell membranes consist of a multitude of lipids, proteins and some carbohydrate. Some components can be isolated from the membrane and then reassembled to have a particular membrane function. This procedure is called membrane reconstitution. The reconstitution of a membrane function by the controlled reassembly of the solubilized membrane components could demonstrate the relationship between the components and the partial function of the specific membrane components.

Most reconstitution begins with solubilizing the membrane using detergent. The membrane proteins are now present as mixed micelles of protein, detergent and perhaps some of the original lipid. They are then separated by column chromatography and/or density gradient centrifugation. The desired phospholipids are added to the selected components and the detergent removed by dialysis or using polystyrene beads. During the removal of detergent, the phospholipids and protein aggregate to form vesicles with the integral membrane protein inserted within the bilayer.

Occasionally, membrane patches in which the protein forms a crystalline array, are obtained upon the removal of detergent ( Weiss et al, 1986 and Jap. B. K., 1988). The experimental factors that may lead to the formation of crystalline membrane patches on reconstitution, instead of vesicles, are not clearly understood yet. But, it seems that the structure of the products formed in 
reconstitution can depend critically on the type of lipids used. Popot et al. (1981) obtained nicely sealed protein-lipid vesicles of the Acetylcholine receptor with soybean lecithin, but not with egg phosphatidylcholine, which under the same experimental conditions, formed membrane sheets.

There is some experimental evidence implying that the lipids of Halobacterium halobium play a critical role in the crystalline aggregation of bR. Bacteriorhodopsin can be solubilized from the purple membrane by using Triton $X-100$, without the loss of its chromophore. If Triton $X-100$ is removed from the solubilized sample by dialysis, the crystalline membrane patches with the same density as native purple membrane are regenerated (Cherry et al,1978). But, if the requisite quantity of DMPC (Dipalmitoylphospatidylcholine) is added to the solubilized sample and then Triton $X-100$ is removed from the sample, unilamellar vesicles containing bacteriorhodopsin are formed instead of membrane patches (Cherry et al., 1978). Above the melting temperature of DMPC, the protein in the vesicles does not appear to have any crystalline order judging from the $X$-ray diffraction pattern. But considering the fact that in the native cell membranes of Halobacterium halobium, $b R$ is localized within the purple membrane patches with crystalline order, it can be concluded that the lipids of Halobacterium halobium play a critical role in the crystalline aggregation of bR. Hence, the lipids extracted from purple membrane according to Kates, M. et al., (1982) have been tried for two-dimensional crystallization of halorhodopsin, in this thesis work. 
B. Necessity of two-dimensional crystals for high-resolution electron microscopy.

Biological material is pretty sensitive to radiation damage from the electron beam. The safe dose to preserve high resolution $(5 \AA)$ information is on the order of magnitude of 1 electron/ $\AA^{2}$ (Glaeser, R. M., 1975, Unwin \& Henderson 1975). With this order of low dose, the noise level in the picture is so high as to obscure the image contrast. The only way to overcome this problem is to superimpose a large number of identical objects. With a twodimensional crystalline sample, superimposing many images can easily be done by computing the Fourier transform of the image of the periodic object. The inverse Fourier transform, using only the values on the reciprocal lattice, is equivalent to the superposition of all unit cells in the crystalline array.

C. Lipid composition of Halobacterium halobium membrane .

Polar lipids constitute about $90 \%$ of the total lipids. The composition of polar lipids in whole cells (as well as in PM) is simple (Table 5-1, Kates et al., 1982). Only two major components are present, PGP (phosphatidylglycerolphosphate) $70 \mathrm{~mol} \%$ and GLS (glycolipid sulfate), two other components, PGS (phosphatidylglycerosulfate) and PG (phosphatidylglycerol) being present in low amounts ( 4 and $5 \mathrm{~mol} \%$ respectively). The structures of the polar lipids are shown in Fig. 5-1. These lipids are unusual in that each contains negatively charged polar head groups, as well as 
highly branched hydrocarbon chains linked by ether groups to the glycerol moleties.

Neutral lipids, accounting for about $10 \%$ of the total lipids, consists of squalenes, vitamin MK-8, bacterioruberins (C50 red pigments) and retinal, which is from bacteriorhodopsin; the composition of neutrai lipid is given in Table 5-1. 


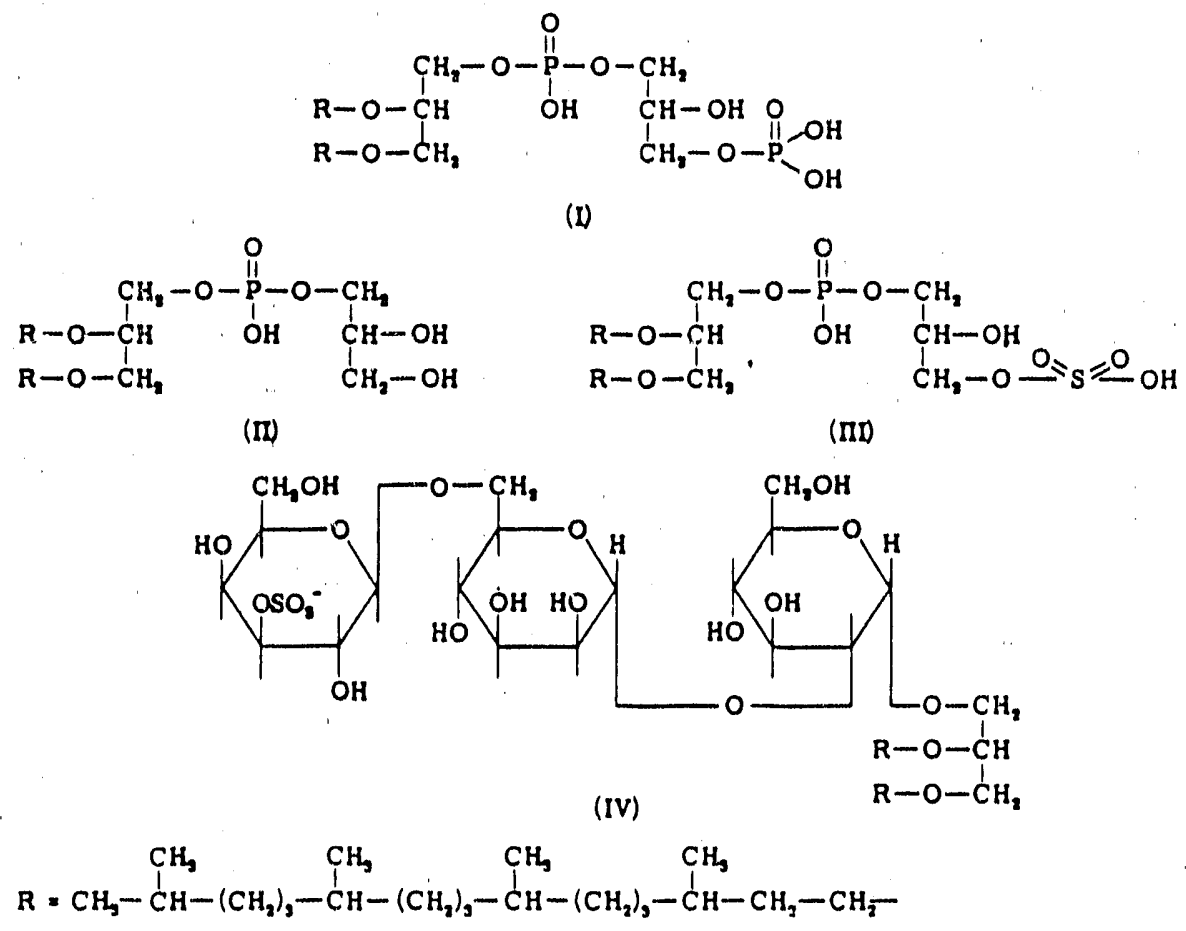

Fig. 5-1. Structures of major polar lipids in Halobacteria halobium: I, phosphatidylglycerolphosphate (PGP); II, phosphatidylglycerol (PG); III, phosphatidyl glycerosulfate (PGS); IV, glycolipid sulfate (GLS). 
Table 5-1

Lipid composition of Halobacterium halobium whole cell membrane and of purple membrane (PM).

$\begin{array}{llll} & \text { Whole cells } & \text { Purple membrane } \\ \text { Lipid components MW Mol.\% } & \text { Mol.\% } & \text { Mol per unit cell }\end{array}$

Neutral lipids

$\begin{array}{lllcl}\text { Squalenes } & 410 & 9 & 10 & 3 \\ \text { Vitamin MK-8 } & 716 & 1 & 2 & 0.5 \\ \text { Retinal } & 284 & 0.3 & 12 & 3 \\ \text { Bacterioruberins } & 740 & 2 & 0 & 0\end{array}$

Polar lipids

$\begin{array}{lcccc}\text { PG } & 830 & 4 & 5 & 1.5 \\ \text { PGP } & 930 & 58 & 49 & 16 \\ \text { PGS } & 920 & 4 & 4 & 1.5 \\ \text { GS } & 1240 & 17 & 22 & 8\end{array}$


D. Reconstitution of bacteriorhodopsin.

It is easy to get a large amount of bacteriorhodopsin $(200 \mathrm{mg}$ from a 12 liter culture using ET1001 strain). But halorhodopsin is only available in relatively small amounts $(12 \mathrm{mg}$ from an 80 liter culture). Considering the many similarities between $b R$ and $h R$, it is possible that information obtained from reconstitution of $b R$ could also be applied to hR. Hence, reconstitution of $b R$ has been investigated as a model system for hR.

1. Recrystallization of purple membrane using $\mathrm{C}_{12} \mathrm{Eg}_{9}$.

$\mathrm{C}_{12} \mathrm{Eg}$ appears to be the best detergent to keep halorhodopsin intact, as described in Chapter III. Also, hR purified in the presence of $\mathrm{C}_{12} \mathrm{Eg}_{9}$, appears to be a trimer, judging from the molecular weight estimated though molecular sieve chromatography and from the presence of exciton splitting in the visible circular dichroism spectrum (Sugiyama \& Mukohata,1984). The trimer conformation of purified $h R$ might be helpful for the crystallization of the protein, considering the fact that $b R$ trimer forms a unit cell in the purple membrane, although monomeric bR can also be crystallized as in the orthorhombic two-dimensional crystal (Michel et al, 1980).

But, $\mathrm{C}_{12} \mathrm{Eg}$ has a very low critical micelle concentration (CMC), 0.07-0.1 $\mathrm{mM}$ at $0 \cdot 0.05 \mathrm{M} \mathrm{Na}+$ (Mast et al., 1975): it is very difficult to remove by dialysis. The situation becomes aggravated by the fact that $h R$ in the presence of $\mathrm{C}_{12} \mathrm{Eg}_{9}$ should be kept in high 
ionic strength (more than $2 \mathrm{M} \mathrm{NaCl}$ ), where the $\mathrm{CMC}$ value of $\mathrm{C}_{12} \mathrm{Eg}$ is much lower than that in low lonic strength.

Another important factor in reconstitution is that the CMC value of a detergent may not be the same for pure detergent micelles, protein-detergent mixed micelles and lipid-detergent mixed micelles. We can distinguish between two cases; the CMC of protein-detergent mixed micelles is lower. than that of lipiddetergent mixed micelles: the CMC of protein-detergent mixed micelles is higher than that of lipid-detergent mixed micelles. In the first case, during the removal of detergent, lipid vesicles are. formed while proteins are still soluble. Then later as the concentration of detergent drops further, proteins can be either inserted into lipid vesicles or form aggregates. In this case, the size of the protein crystalline array, if any, is limited by that of the lipid vesicles, which usually is smaller than $0.1 \mu \mathrm{m}$. In the second case, during the removal of detergent, protein-lipid-detergent complexes can be formed in the presence of the requisite amount of lipiddetergent micelles. Then later either lipid-protein vesicles or lipidprotein bilayers (membrane patches) can be formed. Mechanisms of reconstitution for the above described cases are schematically represented in Fig 5-2. Here the important point is that large crystalline membrane patches useful for high-resolution electron microscopy can only be obtained from the second case.

In this section we describe experiments in which $b R$ was solubilized from purple membrane by using $C_{12} E 9$. Then $C_{12} E 9$ was removed from the solubilized sample by dialysis to see if two. dimensional crystals of the protein could be regenerated. 
A)
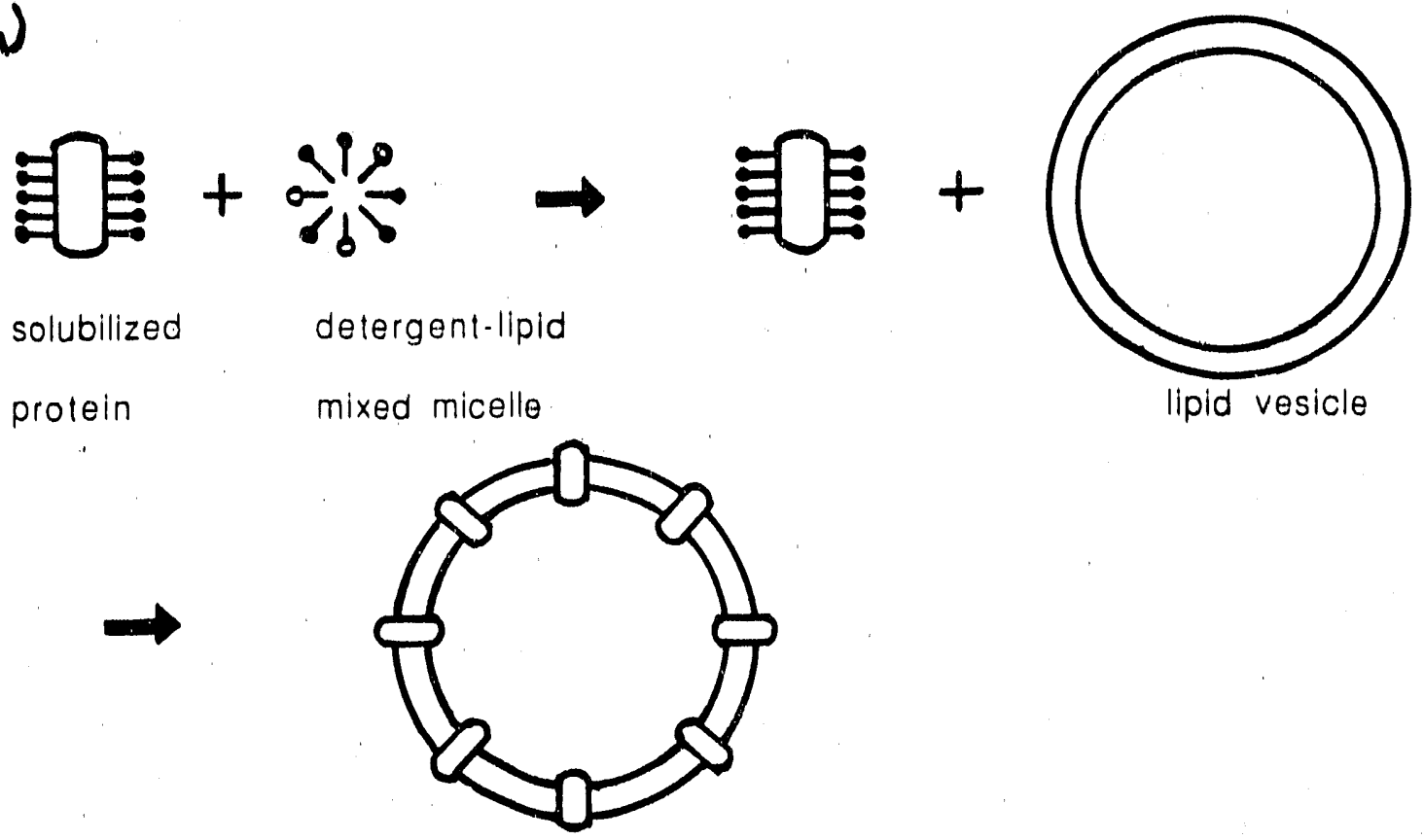

protein-lipid vesicle

B)

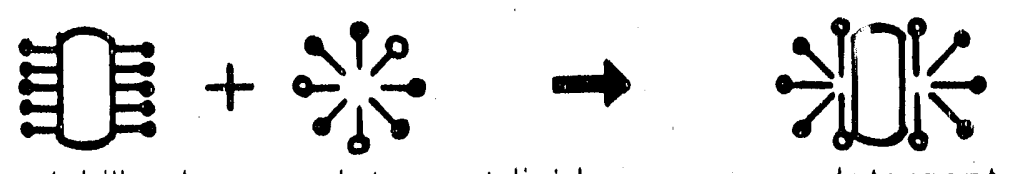

solubilized

detergent-lipid

detergent-lipid-protein

protein

mixed micelle

mixed micelle

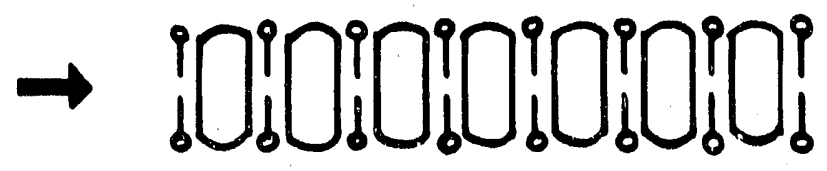

lipid-protein bilayer

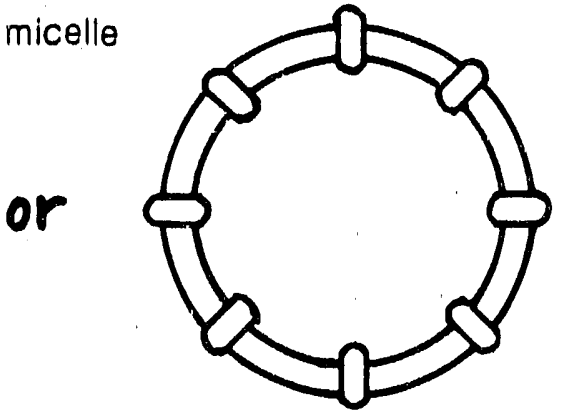

protein-lipid vesicle

Fig. 5-2. A) and B) illustrates the mechanism of reconstitution for the cases that CMC of protein-detergent complex is lower or higher than that of lipid-detergent micelle respectively. 
Materials and Methods.

Preparation of solubilized bacteriorhodopsin.

H. halobium ET 1001 strain was grown in 12-liter culture and harvested according to Oesterhelt \& Stoecknius (1974). Harvested cells were suspended in $200 \mathrm{ml}$ of $4 \mathrm{M} \mathrm{NaCl}$ and lysed by dialysis in the presence of $10 \mathrm{mg}$ of DNAase at $4{ }^{\circ} \mathrm{C}$ for $18 \mathrm{hr}$ against 6 liters of $10 \mathrm{mM}$ MOPS $\mathrm{pH} 7.0$ buffer. The lysate was cleared of large debris by centrifugation (at $2,000 \mathrm{~g} 15 \mathrm{~min}$ ), and then centrifuged at $20,000 \mathrm{~g}$ for $1 \mathrm{hr}$. The supernatant is discarded and the purple sediment was resuspended in $300 \mathrm{ml}$ of distilled water $\left(4^{\circ} \mathrm{C}\right)$. The cycle of resuspension and centrifugation was repeated four times. The purity of the protein was checked by SDS gel electrophoresis. 20 $\mathrm{mg}$ of the purified purple membrane was incubated with $20 \mathrm{ml}$ of $1 \%$ $\mathrm{C}_{12} \mathrm{Eg}_{2}, 50 \mathrm{mM} \mathrm{Na}$-Acetate $\mathrm{pH} .5 .0$ buffer (protein : detergent ratio is $1: 10$ ) at $30^{\circ} \mathrm{C}$ for $4 \mathrm{hrs}$. Unsolubilized material (around $20 \%$ of the membrane) was removed by centrifugation at 150,000g for 2 hrs. The solubilized protein was concentrated to $2 \mathrm{ml}$ by ultrafiltration (Amicon YM100) and then mixed with $2 \mathrm{ml}$ of $4 \mathrm{M} \mathrm{NaCl}, 1 \% \mathrm{C}_{12} \mathrm{Eg}_{9}, 50$ $\mathrm{mM}$ Na-Acetate pH. 5.0 buffer. The final sample has a protein concentration of $4 \mathrm{mg} / \mathrm{ml}$.

Dialysis of the solubilized sample.

$1 \mathrm{ml}$ of the solubilized sample was dialyzed against $500 \mathrm{ml}$ of $2 \mathrm{M} \mathrm{NaCl}, 100 \mathrm{mM} \mathrm{Na}$-Acetate $\mathrm{pH} .5 .0$ buffer, at $4{ }^{\circ} \mathrm{C}$ in the dark, with daily changes of the whole buffer, for 2 weeks. 
Results and discussion.

Initially, sulubilization of puiple membrane was tried with the same buffer as used for the purification of $h \mathrm{R}\left(2 \mathrm{M} \mathrm{NaCl}, 1 \% \mathrm{C}_{12} \mathrm{Eg}\right.$ and $10 \mathrm{mM}$ MOPS pH 7.0 buffer). But it was soon found to be dificult to solubilize purple membrane in solutionc with an ionic strength above $0.1 \mathrm{M} \mathrm{NaCl}$. Then it was also found that $b R$ solubilized in $\mathrm{C}_{12} \mathrm{Eg}$ is not very stable at $\mathrm{pH}$ 7.0. Hence all the buffers used in this experiment have $\mathrm{pH} 5.0$ and the buffer used for the solubilization has a low ionic strength ( $50 \mathrm{mM} \mathrm{Na-Acetate).} \mathrm{The} \mathrm{absorption} \mathrm{spectrum}$ of the solubilized $b R$ is shown in Fig. $5-3$. It has a visible absorption peak at $561 \mathrm{~nm}$ which is slightly red-shifted from the peak at 568 $\mathrm{nm}$ for purple membrane. The ratio of the absorbance maxima at $280 \mathrm{~nm}$ and $561 \mathrm{~nm}\left(\mathrm{~A}_{280} / \mathrm{A}_{561}\right)$ is 1.51, which is smaller than 2.0 for purple membrane ( $A_{280 / A 568)}$, indicating that the preparation is free of light scattering and denaturation.

After 5 days of dialysis against the buffer without detergent, some membrane patches precipitated at the bottom of the dialysis bag. They appeared to have the same density as native purple membrane, judging from the sucrose gradient experiment. Under electron microscopy, these membrane patches gave nice electron diffraction patterns with the same unit cell as purple membrane. A powder diffraction pattern from such patches is shown in Fig. 5-4. Hence, it seemed that $\mathrm{C}_{12} \mathrm{E}_{9}$ can be used for the crystallization of halorhodopsin. 


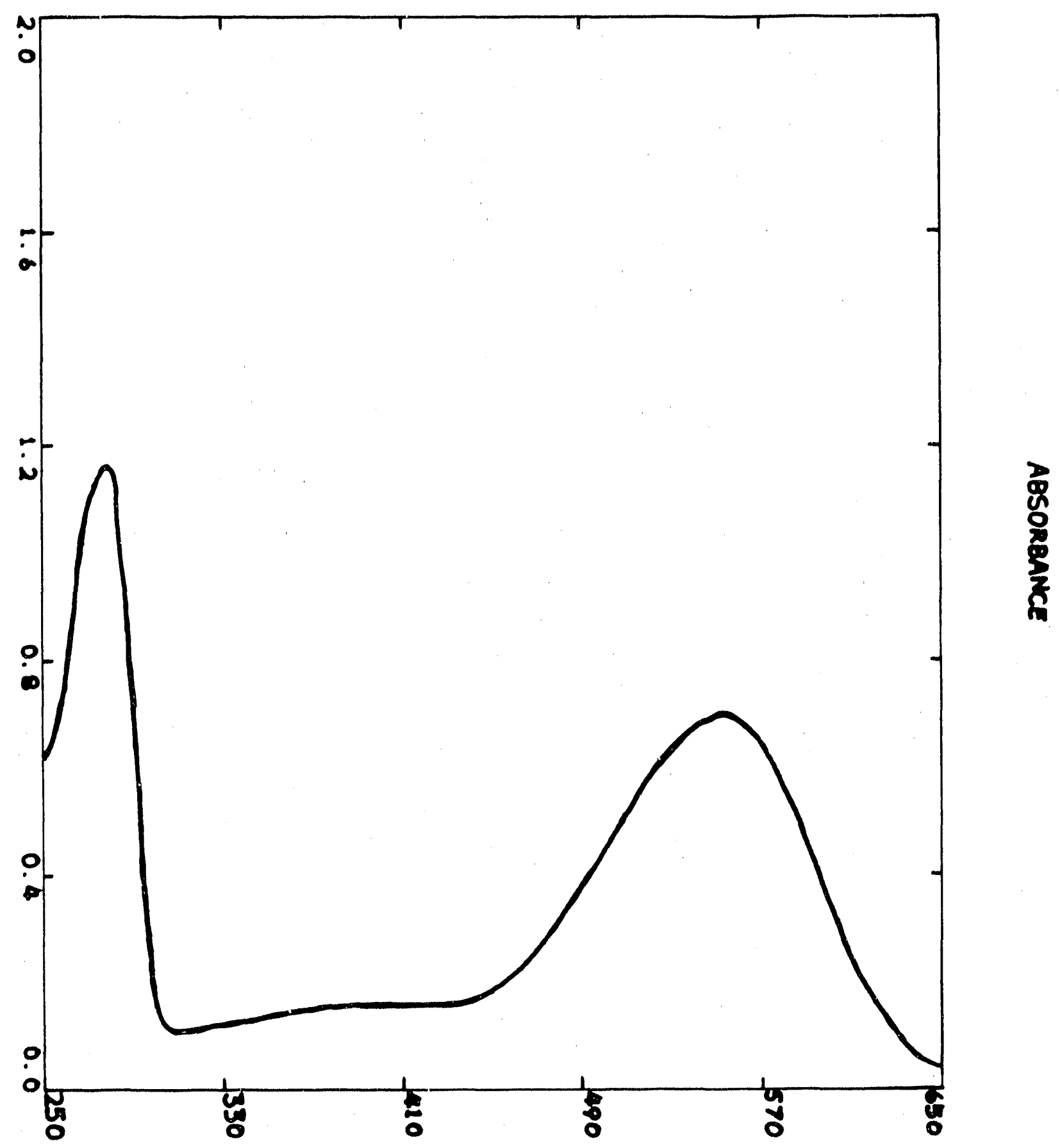

Fig. 5-3. The absorption spectrum of bacteriorhodopsin solubilized in $\mathrm{C}_{12} \mathrm{E}_{9}$ 


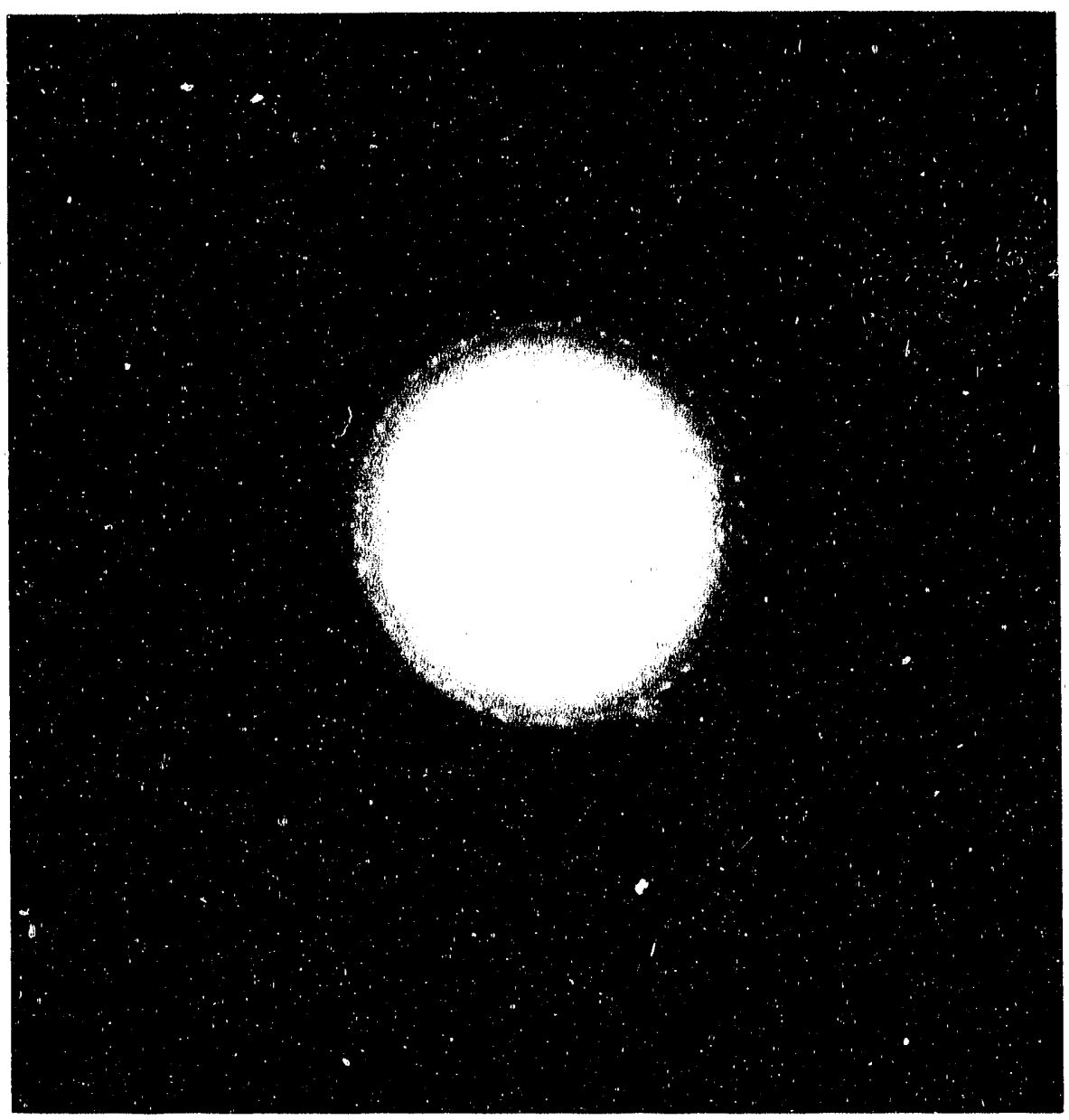

Fig. 5-4. Powder electron diffraction pattern from recrystallized bacteriornodopsin.

XBB 903-2552 
2. Reconstitution of bacteriorhodopsin with the purple membrane lipids.

Bacteriorhodopsin was prepared in the same way as halorhodopsin was purified. Purple membrane was solubilized in $\mathrm{C}_{12} \mathrm{Eg}$ and then the solubilized protein was run through the chromatography columns used in the purification of hR. Then PM lipids solubilized in $\mathrm{C}_{12} \mathrm{Eg}$ were added to the protein, with protein:lipid ratios $(\mathrm{w} / \mathrm{w})$ ranging from $1: 0.5$ to $1: 2$. The mixtures were dialyzed to remove the detergent.

Materials and Methods.

Preparation of bacteriorhodopsin.

$40 \mathrm{mg}$ of bacteriorhodopsin was solubilized from purple membrane with $\mathrm{C}_{12} \mathrm{Eg}_{9}$, according to the procedure described in the earlier section. The solubilized protein was run through a phenylsepharose column $(25 \mathrm{~cm} \times 30 \mathrm{~cm})$ and an hydroxylapatite column ( 3 $\mathrm{cm} \times 6 \mathrm{~cm})$ successively, which had been equilibrated with $4 \mathrm{M} \mathrm{NaCl}$, $0.5 \% \mathrm{C}_{12} \mathrm{Eg}$ and $10 \mathrm{mM}$ MOPS $\mathrm{pH} 5.0$ buffer. Then the protein was concentrated to $5 \mathrm{mg} / \mathrm{ml}$ by ultrafiltration. The amounts of phopholipids in the solubilized protein sample before and after chromatography steps was compared by measuring the amounts of phosphorus in the samples (Fiske \& Subbarow, 1925). 
Preparation of $\mathrm{PM}$ lipids solubilized in $\mathrm{C}_{12} \mathrm{Eg}$.

Lipids were extracted from purple membrane according to Kates et al. (1982). A suspension of $100 \mathrm{mg} P M$ in $24 \mathrm{ml}$ of distilled water was diluted with $60 \mathrm{ml}$ of methanol and stirred in the dark under nitrogen for $60 \mathrm{~min}: 30 \mathrm{ml}$ of chloroform was added and the stirring was continued for $30 \mathrm{~min}$. The mixture was centrifuged, and the supernatant was collected. The pellet was extracted with $42 \mathrm{ml}$ of methanol-water $(2.5: 1)$ for $10 \mathrm{~min}$ with stirring, $15 \mathrm{ml}$ of chloroform was added, and stirring was continued for $30 \mathrm{~min}$. After centrifugation the combined supernatants were diluted with $45 \mathrm{ml}$ of chloroform and $45 \mathrm{ml}$ of $0.2 \mathrm{M} \mathrm{KCl}$ with gentle mixing and the phases were allowed to separate overnight in a separating funnel. The lower chloroform phase was removed and dried under a stream of nitrogen gas. Dried lipids were dissolved in $10 \mathrm{ml}$ of chloroform. The amount of lipids was determined by measuring the amount of phopsphorus (Fiske \& Subbarow 1925) upon the assumption that phospholipid accounts for $62 \%$ weight of PM lipids and the average molecular weight of phospholipids in PM is 920 (Kates et al. 1982). The amount of extracted lipids from $100 \mathrm{mg}$ of PM was around 20 $\mathrm{mg} .20 \mathrm{mg}$ of $\mathrm{C}_{12} \mathrm{Eg}$ is added to the $20 \mathrm{mg}$ of $\mathrm{PM}$ lipids in chloroform. After chloroform was evaporated from the lipids, $1 \mathrm{ml}$ of $1 \%$ C12E9, $\quad 0.1 \mathrm{~N} \mathrm{Na-Acetate} \mathrm{pH} 5.0$ buffer solution was added to the dried lipid and the solution was sonicated until it became clear. The sample was centrifuged $(100,000 \mathrm{~g}$ for $30 \mathrm{~min})$ to remove unsolubilized lipids (usually there were almost none). Then $1 \mathrm{ml}$ of $1 \% \mathrm{C} 12 \mathrm{E} 9,4 \mathrm{M} \mathrm{NaCl}, 0.1 \mathrm{~N} \mathrm{Na}$-Acetate $\mathrm{pH} 5.0$ buffer solution was added to the sample so that the sample has $2 \mathrm{M} \mathrm{NaCl}$ ionic strength. 
Here one important thing is that dried lipid should be suspended in solution with low ionic strength. If dried lipid is suspended in solution with $2 \mathrm{M} \mathrm{NaCl}$, the solution will never become clear. The resulting lipid solution had a lipid concentration of $10 \mathrm{mg} / \mathrm{ml}$ and a lipid:detergent ratio of $1: 2$.

Membrane reconstitution.

Bacteriorhodopsin and purple membrane lipids solubilized in $C_{12} E g$ as described in the earlier paragraphs were mixed with various lipid to protein ratios of between $0.5: 1$ to $2: 1$. according to table 5-2. A protein sample without any added lipid was also included as a control experiment. The protein concentration of each sample was set to $1 \mathrm{mg} / \mathrm{ml}$ by adding the requisite amount of $1 \%$ $\mathrm{C}_{12} \mathrm{Eg}, 2 \mathrm{M} \mathrm{NaCl}, 0.1 \mathrm{~N} \mathrm{Na}$-Acetate $\mathrm{pH} 5.0$ buffer. Mixed materials were briefly sonicated $(1 \mathrm{~min}$.$) and dialyzed against 500 \mathrm{ml}$ of $2 \mathrm{M}$ $\mathrm{NaCl}, 0.1 \mathrm{M} \mathrm{Na}$-Acetate $\mathrm{pH} 5.0$ buffer at $4{ }^{\circ} \mathrm{C}$, with daily change of the whole buffer, for 2 weeks.

Table 5-2

Sample\# Protein : Lipid Protein $(5 \mathrm{mg} / \mathrm{ml})$ Lipid $(10 \mathrm{mg} / \mathrm{ml})$ buffer

$\begin{array}{ccccccc}1 & 1 & : & 0 & 100 \mu 1 & 0 & 400 \mu 1 \\ 2 & 1 & : & 0.5 & 100 \mu 1 & 25 \mu 1 & 375 \mu 1 \\ 3 & 1 & : & 1 & 100 \mu 1 & 50 \mu 1 & 350 \mu 1 \\ 4 & 1 & : & 2 & 100 \mu 1 & 100 \mu l & 300 \mu 1\end{array}$


Results and Discussion.

Measurement of the amount of phosphorus in the purified protein showed that about half of phosphorus lipids bound to the protein in purple membrane were removed after the chromatography steps. After 3.5 days of dialysis, some membrane patches precipitated at the bottom of the dialysis bag of samples \#2-\#4. But no patch was formed from the sample \#1, which was a control experiment without any added lipids. The patches were formed earlier for the sample containing more lipids, implying that the speed of formation of the membrane depends on the concentration of the lipids. The densities of the samples \#3 (lipid:protein; 1:1 $w / w), \# 4$ (lipid:protein; $2: 1 \mathrm{w} / \mathrm{w}$ ) and purple membrane were compared by centrifugation on a continuous sucrose gradient $20-50$ $\%$ (Fig. 5-5). The sample \#3 has a single band in the sucrose gradient at the same height as that of purple membrane, indicating that the patches in the sample \#3 has the same density as purple membrane. But the sample \#4 has two closely spaced bands with the lower band located at the same height as that of purple membrane. Two bands of the sample \#4 can be well separated through the use of a step sucrose gradient. The patches in the upper band have diameters larger than $1 \mu \mathrm{m}$. On the other hand, the patches in the lower band have diameters smaller than $0.5 \mu \mathrm{m}$. But both of them showed identical diffraction patterns with that of purple membrane (Fig. 56). The difference in density with the same lattice constant indicates that the membrane patches in the upper band have the same unit cell as purple membrane, but a small amount of excess lipids may be located in the boundary of the membrane. 


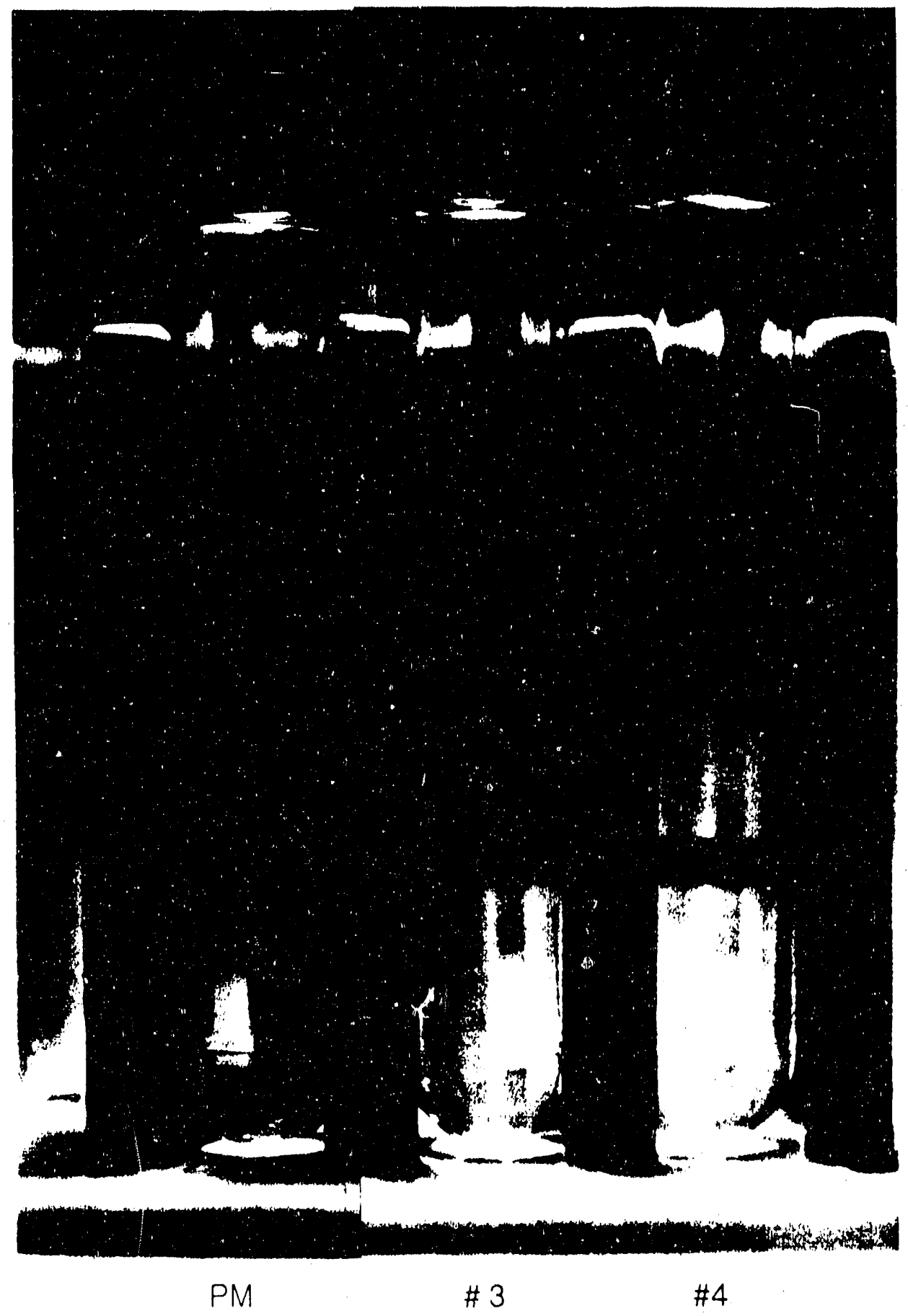

Fig. 5-5 Purple membrane and sample \# 3 and 4 of reconstituted bR on a $20 \%-50 \%$ continuous sucrose gradient. 


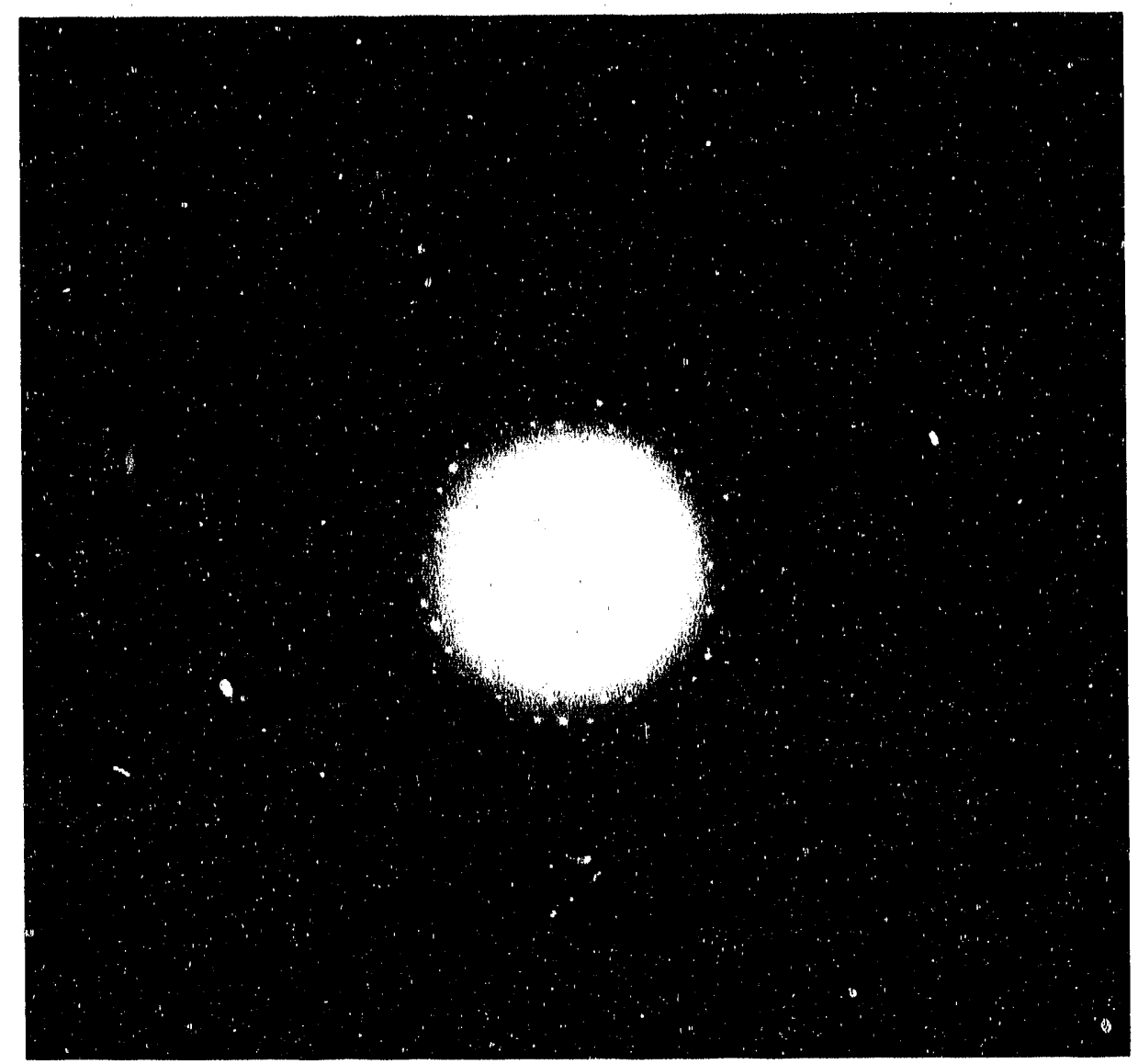

Fig, 5-6 Electron diffraction pattern from reconstituted bR. 
The most important facts from this experiment are that delipidated bacteriorhodopsin can not form a two-dimensional crystal. On the other hand, even if the starting lipid:protein ratio is much higher than that of purple membrane (lipid:protein; $1: 3 \mathrm{~W} / \mathrm{w}$ ), crystalline patches are formed which have almost the same lipid:protein ratio as purple membrane.

The above facts may be explained by the hypothesis that during the removal of detergent, a certain number of PM lipids can be bound to bacteriorhodopsin, and then only the lipid-protein complex with the proper stoichiometrycan form two-dimensional crystals.

To study the effect of protein concentration on reconstitution, another set of experiments was tried as described in Table 5-3, where the protein concentration was set to $3.3 \mathrm{mg} / \mathrm{ml}$. To $\mathrm{my}$ surprise, just after the protein and purple membrane lipids were mixed, some purple-colored materials precipitated. After brief centrifugation $(10,000 \mathrm{~g}$ for $10 \mathrm{~min})$, all the protein in samples $\# 2$ and \#3 got spun down, and about half of the protein in sample \#1 did that. Precipitated materials turned out to be small membrane 


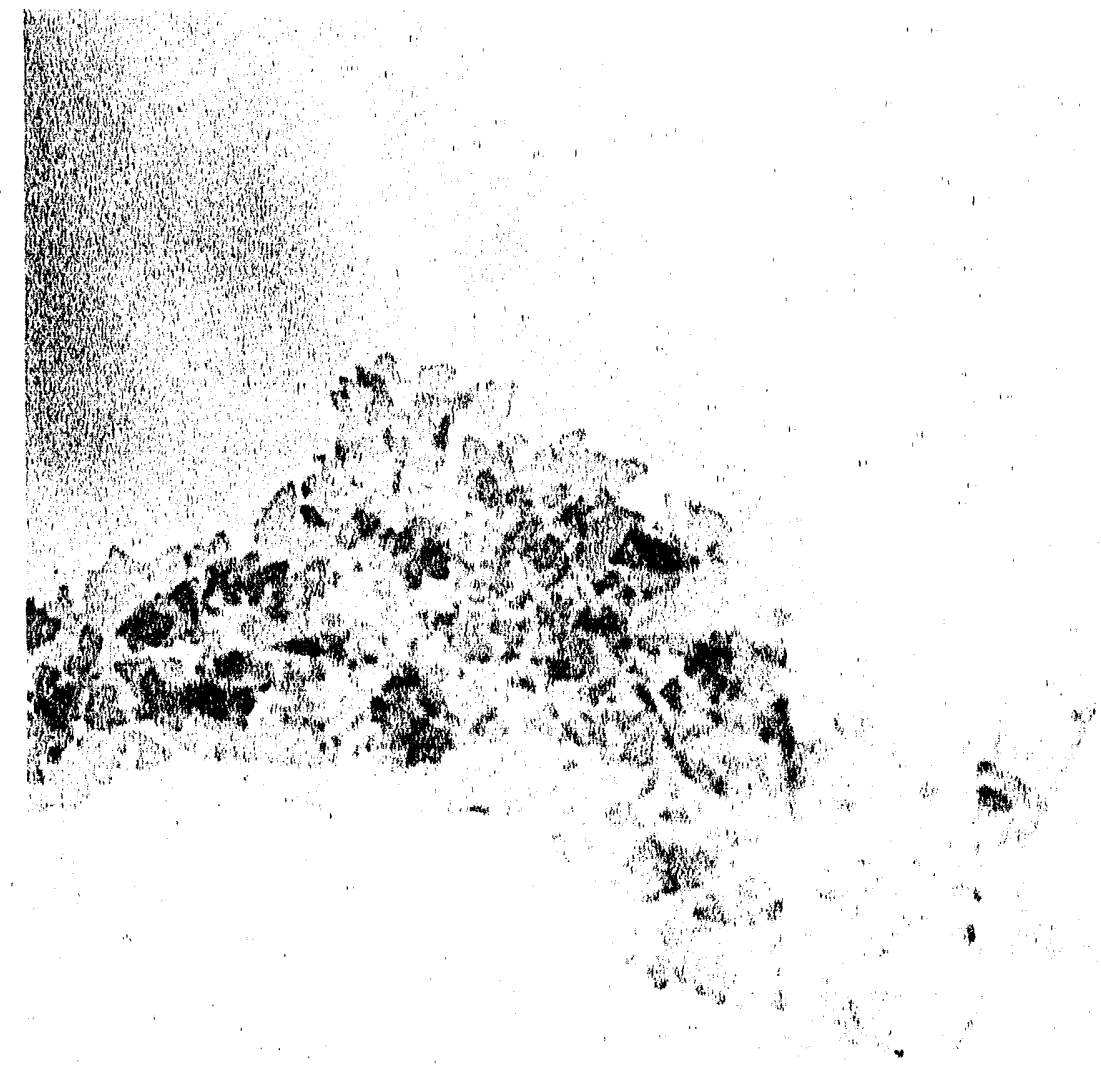

Fig.5-7 The image of spontaneously formed bR membrane patches. 


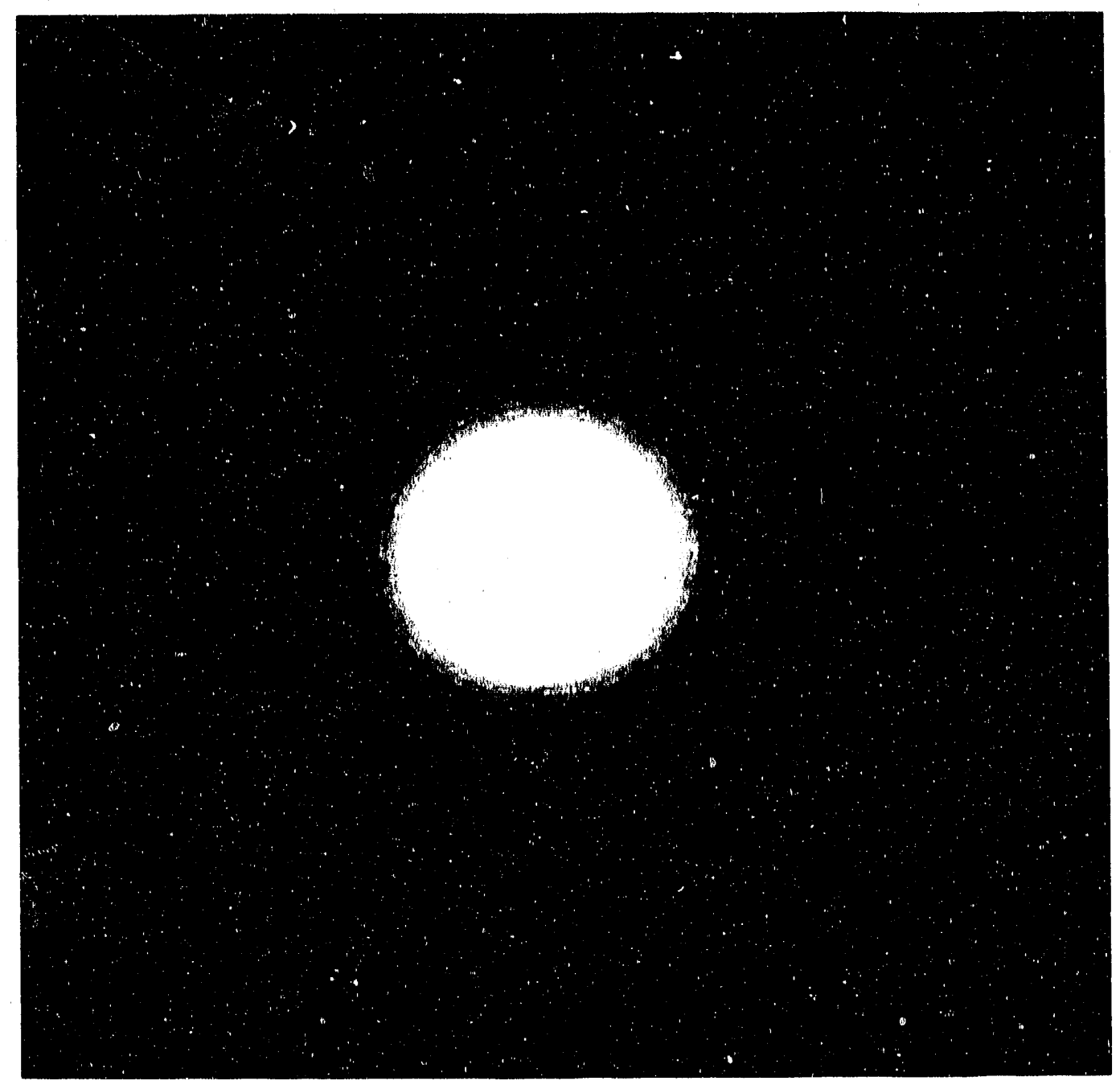

Fig. 5-8 Powder electron diffraction pattern from spontaneously formed $b R$ membranes. 
patches of size around $0.1 \mu \mathrm{m}$, which gave a pwder-type electron diffraction pattern (Fig. 5-7, Fig. 5-8). This spontaneous crystallization can be explained as follows. At high ionic strength ( $2 \mathrm{M} \mathrm{NaCl}$ ), the affinity between purple membrane lipids and $b R$ is higher than that between $\mathrm{C}_{12} \mathrm{Eg}_{9}$ and $\mathrm{bR}$. Hence purple membrane lipids replaced the detergent bound to $\mathrm{bP}$ to form lipid-protein complex molecules, without the removal of the detergent. Above a certain protein concentration, the lipid-protein complex molecules can form crystalline membrane patches instantly.

Although membrane patches obtained from the above-described spontaneous crystallization are a little bit too small for highresolution electron microscopy, the above phenomenon can be used as a general technique. If we know the condition where the affinity between some membrane protein and certain lipids is higher than that between the protein and some detergent, the membrane protein solubilized in the detergent can be crystallized by just mixing with the lipids under the right condition.

Table 5-3

Sample\# Protein : Lipid Protein Lipid buffer $(10 \mathrm{mg} / \mathrm{ml}) \quad(10 \mathrm{mg} / \mathrm{ml})$

\begin{tabular}{|c|c|c|c|c|c|}
\hline 1 & 1 & 0.5 & $100 \mu \mathrm{l}$ & $50 \mu 1$ & $150 \mu l$ \\
\hline S & 1 & 1 & $100 \mu 1$ & $100 \mu 1$ & $100 \mu l$ \\
\hline & 1 & 2 & $100 \mu l$ & $200 \mu 1$ & 0 \\
\hline
\end{tabular}


E. Reconstitution of halorhodopsin.

After obtaining positive results of bR reconstitution with PM lipids, reconstitution of $h R$ was tried in the same way. Purified halorhodopsin and PM lipids were mixed with four different lipid:protein ratios $(1: 0.5,1: 1,2: 1$ and $3: 1)$ as described in Table 54. The protein concentration was set to $1 \mathrm{mg} / \mathrm{ml}$. All the operations were carried out in the same way as in the reconstitution of $b R$, except that all the buffer used had $\mathrm{pH} 7.0$ instead of $\mathrm{pH}$. 5.0. Also the PM lipids prepared are strongly acidic and hR is not so stable at acidic $\mathrm{pH}$ values. Hence, $\mathrm{PM}$ lipids were resuspended in $1 \% \mathrm{C}_{12} \mathrm{Eg}_{9}, 0.5$ $\mathrm{M}$ Na-phosphate $\mathrm{pH} 7.0$ buffer to make sure that the $\mathrm{pH}$ remained neutral.

Table 5-4. Reconstitution of hR at a protein concentration of $1 \mathrm{mg} / \mathrm{ml}$.

$\begin{array}{lcccccc}\text { Sample\# } & \text { Protein : Lipid } & \text { Protein } & \text { Lipid } & \text { buffer } \\ & & & & (5 \mathrm{mg} / \mathrm{ml}) & (10 \mathrm{mg} / \mathrm{ml}) \\ 1 & 1 & : & 0.5 & 100 \mu l & 25 \mu l & 375 \mu 1 \\ 2 & 1 & : & 1 & 100 \mu l & 50 \mu l & 350 \mu 1 \\ 3 & 1 & : & 2 & 100 \mu l & 100 \mu l & 300 \mu 1 \\ 4 & 1 & : & 3 & 100 \mu l & 150 \mu l & 250 \mu 1\end{array}$

Nothing precipitated at the bottom of the dialysis bag, even after 10 days of dialysis, in contrast to $\mathrm{bR}$ reconstitution. After 2 weeks of dialysis, all the samples were taken out of the dialysis 
bags and centrifuged briefly $(10,000 \mathrm{~g}$ for $10 \mathrm{~min})$. Some purple pellet was obtained from only the sample \#4. The peliet consists of some porous membranes, but no electron diffraction was obtained.

From the previous experiment, it is obvious that $b R$ and $h R$ do not behave in the same way. Hence, another set of experiments was tried with the higher protein concentration $2.5 \mathrm{mg} / \mathrm{ml}$ as described in Table 5-5. No spontaneous crystallization was observed after mixing the protein and lipids.

Table 5-5. Reconstitution of $h R$ at a final protein concentration of $2.5 \mathrm{mg} / \mathrm{ml}$.

\begin{tabular}{|c|c|c|c|c|c|}
\hline Sample\# & Protein & Lipid & Protein & Lipid & buffer \\
\hline & & & $(10 \mathrm{mg} / \mathrm{ml})$ & (10. ms & \\
\hline 1 & 1 & 1 & $100 \mu l$ & $100 \mu l$ & $300 \mu 1$ \\
\hline 2 & 1 & 2 & $100 \mu l$ & $200 \mu l$ & $200 \mu 1$ \\
\hline 3 & 1 & 3 & $100 \mu 1$ & $300 \mu l$ & 100 \\
\hline
\end{tabular}

After 4 days of dialysis, some membrane patches precipitated at the bottom of the sample with the lipid:protein ratio of $3: 1$. But nothing precipitated from the other two samples, even after one month of dialysis. After one month of dialysis, the sample \#1 and 2 were taken out of the dialysis bags and centrifuged for $10,000 \mathrm{~g}$ for $30 \mathrm{~min}$. But only a small amount of white colored pellet was sedimented from both samples. 
Hence, anther set of experiments were done with the lipid: protein ratios of $1: 1,2: 1,3: 1,4: 1$ and $5: 1$. Again, membrane patches were obtained only from the three latter conditions.

Next, the lipid:detergent ratio was changed from $1: 2$ to $1: 4$ in the added lipid solutions and the reconstitution experiment was repeated, only to get the same results.

The above results could be interpreted as follows; the affinity between $h R$ and PM lipids is weaker than that between the lipids themselves. Thus, unless the concentration of lipid is above a certain value, not enough lipid-protein complexes are formed to make membrane patches. The densities of the patches obtained from three lipid:protein ratios of $3: 1,4: 1$ and $6: 1$, and purple membrane were compared on a continuous sucrose gradient $20-50 \%$ (Fig. 5-9). The sample with the $3: 1$ ratio appears to have the same density as purple membrane and the other two samples have slightly lower values.

Halorhodopsin in the reconstituted membrane seems to be pretty stable at a low ionic strength, in contrast to the protein solubilized in $\mathrm{C}_{12} \mathrm{Eg}$, which loses its chromophore instantly under the same condition. All the patches were examined by electron microscopy. The image of some patches reconstituted with a lipid:protein ratio of $3: 1$ and a detergent:lipid ratio of $1: 2$ is shown in fig. 5-10. The patches have diameters between 1 and $2 \mu \mathrm{m}$ and appear to be single-layer membranes.

But none of the patches gave any electron diffraction spots, contrary to expectation. X-ray diffraction patterns recorded from pellets of the reconstituted $\mathrm{hR}$ membrane did not reveal any 


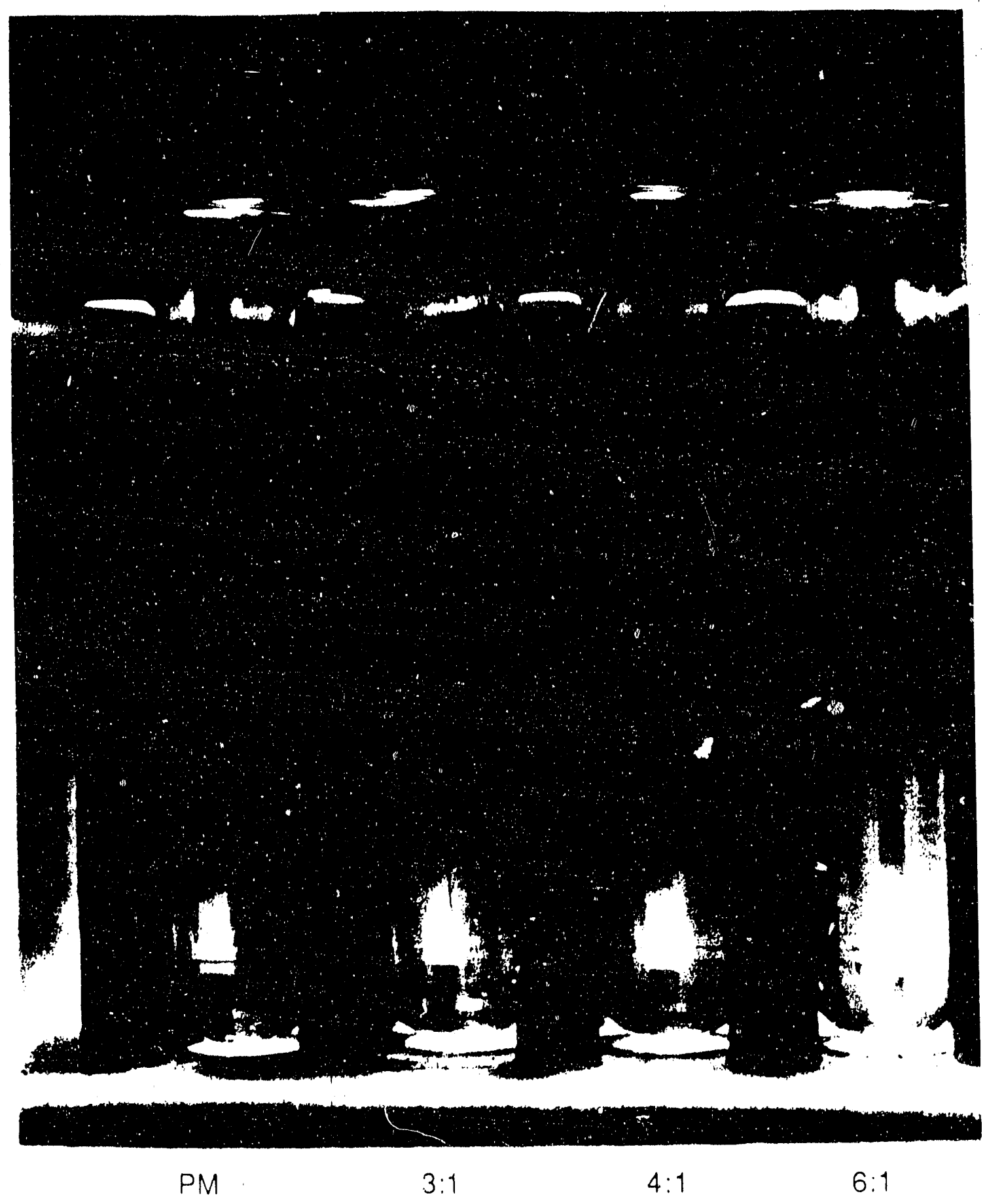

Fig. 5-9. Purple membrane and $h R$ reconstituted with lipid:protein ratios of $3: 4.4$ and $6: 1$ on a continuous morose gradient $20-50 \%$. 
crystalline order either.

Purple membrane partially delipidated through the use of deoxycholate remains in a crystalline state, with but a smaller unit cell (Glaeser et al. 1985). Halorhodopsin membrane patches were treated with cholate or deoxycholate in the hope that there would be stronger interaction and better tendency to crystallize between the proteins with a smaller unit cell. Unfortunately, deoxycholate was found to bleach hR membrane. Cholate treatment worked without the loss of chromophore, but cholate-treated membranes still did not give electron diffraction.

It is really difficult to explain why $h R$ membrane patches which appear to be so similar to purple membrane, did not diffract. Chen, J. et al (1974) showed that Halobacterium lipids alone can not form stable bilayer structures at concentrations above $0.2 \mathrm{M} \mathrm{KCl}$. Hence, under the dialysis condition ( $2 \mathrm{M} \mathrm{NaCl}$ ) used here, membrane patches could form only in the presence of the interaction between proteins. But it seemed that the interaction between halorhodopsin molecules was not strong enough to form long-range crystalline order required to give electron diffraction patterns. More biophysical studies ( for example. flash-induced Linear Dichroismi) to investigate the rotational diffusion or fluidity of halorhodopsin in the reconstituted membrane, are required to understand the overall situation. But those further studies could not be pursued in this thesis work, because of the limited amount of the reconstituted membrane obtained.

One possible reason for the membrane not to diffract is that after the membrane patches were resuspended in low ionic strength 
solution for examination in the electron microscope, the interaction between the proteins became weaker and the crystalline order was lost. That possibility is raised from the report by Sugiyama \& Mukohata (1984) that the CD spectrum of tween-washed membrane containing $h R$ showed exciton coupling between chromophores indicating that $h \mathrm{~h}$ existed as oligomers, but after the membrane had been incubated in low ionic strength solution, the exciton coupling was gone. There is another interesting example which supports the possibility. If purple membrane is washed extensively with low ionic strength solution, the visible spectrum of the membrane is blue-shifted. Such membrane, so-called blue membrane does not give any $X$-ray diffraction pattern, although it has the same density and the same composition of lipids as purple membrane (private communication from Dr. M. P. Heyn).

If the above possibility is true, then that is a big obstacle for high-resolution electron microscopy study, because the membranes in high ionic strength solution can not be applied to an EM grid without forming many salt crystals which block the view. But one possible way to solve this problem is to use frozen hydrated samples. 


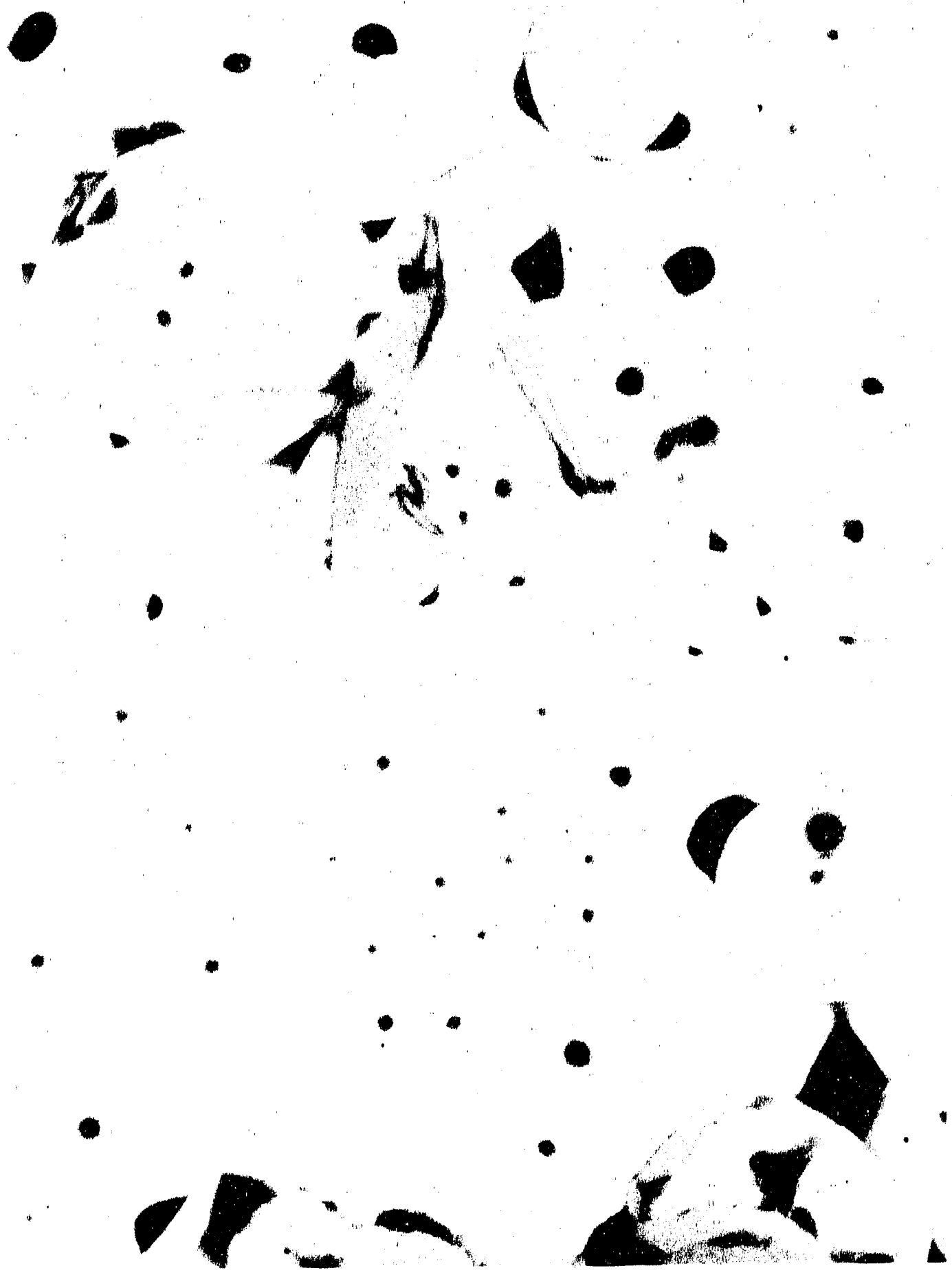

Fig. 5-10 The image of reconstituted hR at the protein concentration of $2.5 \mathrm{mg} / \mathrm{ml}$. 
VI. Conclusion.

In this dissertation work, circular dichroism studies indicated that bacteriorhodopsin and halorhodopsin must have very similar secondary structures. A nice purification procedure was designed to get homogeneous and intact halorhodopsin by the modification of existing purification procedures. Two-dimensional crystallization of halorhodopsin was tried by reconstitution with the purple membrane lipids. It was possible to get hR-containing membrane patches, which are similar to purple membrane in morphology and density. But the hR membrane patches appeared not to have long-range crystalline order of the protein, although the $b R$ membrane reconstituted under the same condition gives nice electron diffraction patterns. What we learned from reconstitution of $b R$ and $h R$ with purple membrane lipids can be summarized as follows.

1. Delipidated bacteriorhodopsin molecules can not form two dimensional crystals by themselves.

2. Even if the starting lipid:protein ratio for reconstitution of $b R$ with purple membrane lipids is $2: 1$ ( $w . / w$.), which is much higher than that of purple membrane (lipid:protein; $1: 3 \mathrm{w} . / \mathrm{w}$. ), crystalline patches are formed with the same unit cell as purple membrane. This fact may be explained by the hypothesis that during the removal of detergent, a certain number of PM lipids can be bound to bacteriorhodopsin and then only the lipid-protein complex, with the proper stoichiometry, can form a two-dimensional crystal. 
3. After $b R$ and purple membrane lipids were mixed at high salt concentration, if the protein concentration was as high as 3.3 $\mathrm{mg} / \mathrm{ml}$, crystalline membrane patches with the same unit cell as purple membrane were formed instantly, without the removal of detergent. This spontaneous crystallization can be explained as follows. At high ionic strength $(2 \mathrm{M} \mathrm{NaCl})$, the affinity between purple membrane lipids and $b R$ is higher than that between $C_{12} E_{9}$ and $b R$. Hence purple membrane lipids replaced the detergent bound to $b R$ to form lipid-protein complex molecules, without the removal of the detergent. Above a certain protein concentration, the lipidprotein complex molecules can form crystalline membrane patches instantly. This phenomenon can possibly be used as a general technique. If we know the condition where the affinity between some membrane protein and certain lipids is higher than that between the protein and some detergent, the membrano protein solubilized in the detergent can be crystallized by just mixing with the lipids under the right condition.

4. Successful reconstitution of halorhodopsin with purple membrane lipids required a high starting lipid:protein ratio (above $3: 1 \mathrm{w} . / \mathrm{w}$.) and higher protein concentration. No spontaneous crystallization was observed. But the reconstituted membranes have almost the same density as purple membrane. This result could be interpreted as follows; the affinity between $h R$ and PM lipids is weaker than that between lipids themselves. Thus, unless the concentration of lipid is above a certain value, not enough lipid-protein complexes are formed 
to make membrane patches. As well as for $b R$, only the lipid-protein complex with the proper stoichiometry can form membrane patches

The absence of long-range crystalline order in reconstituted hR membrane implies that some other subtle factors should be involved to get two-dimensional crystals. More investigations need to be done to characterize the involved factors. It is wished that the information obtained from this experiment is helpful for the attempt to get two-dimensional crystals of other membrane proteins. 
VII. References.

Adler, A., Greenfield, N. and Fasman, G., "Circular dichroism and optical rotatory dispersion of proteins and polypeptides", Meth. in Enz. 27D, 675 (1973).

Alshuth, T., Stockburger, M., Hegemann, P. \& Oesterhelt, D., "Structure of the halorhodopsin", FEBS Letters 179, 55 (1985).

Bayley, H., Huang, K. S., Radhakrishnan. R., Ross, A. H., Takagaki, Y. \& Khorana, H.G., "Site of attachment of retinal in bacteriorhodopsin", Proc. Nat. Acad. Sci. 78, 2225 (1981).

Blanck, A. \& Oesterhelt. D., "The halo-opsin gene. II. sequence, primary structure of halorhodopsin and comparison with bacteriorhodopsin", EMBO J. 6, 265 (1987).

Blaurock, A. E. \& Stoecknius, W., "Structure of the purple membrane", Nature New Biol., 233, 152 (1971).

Chen, J. S., Barton, P., Brown, D. and Kates, M., "Osmometric and microscopic studies on bilayers of polar lipids from the extreme halophile, Halobacterium Cutirubrum", Biochimica et Biophysica Acta. 352, 202 (1974).

Chen, Y., Yang, J. and Chau, K., "Determination of the helix and $B$ form of proteins in aqueous solution by circular dichroism", Biochemistry 13, 3350 (1974).

Cherry, R. J., Muller, U., Henderson, R. \& Heyn, M. P., "Temperaturedependent aggregation of bacteriorhodopsin in dipalmitoyl- and dimyristoyl-phosphatidylcholine vesicles", J. Mol, Biol, 121 $(19,78)$. 
Dannon, A. \& Stoecknius, W., "Phosphorylation in Halobacterium halobium", Proc.. Natl: Acad. Sci., 71, 1234 (1974).

Dunn, R., McCoy, J., Simsek, M., Majumdar, A., Chang, S. H., RajBhandry, U. L. and Khorana, H. G., "The bacteriorhodopsin gene", Proc. Natl. Acad. Sci., 78, 6744 (1981).

Engelman, D. M., Henderson, R., McLachlan, A. D. \& Wallace, B. A., "Path of polypeptide in bacteriorhodopsin", Proc. Nat. Acad. Sci. 77, 2023

Engelman, D. M. \& Zaccai, G., "Bacteriorhodopsin is an inside-out protein", Proc. Natl. Acad. Sci. 77, 5894 (1980).

Fiske, C. H. \& Subbarow, Y., "The colorimetric determination of phosphorus", J. Biol. Chem. 66, 375 (1925).

Flannery, W. L. , "Current status of knowledge of halophilic bacteria", Bacteriol. Rev., 20, 49 (1956).

Fodor, P. A., Ames, J. B., Gebhard, R., van den Berg, E. M. M., Stoecknius, W., Lugtenburg, J. \& Mathies, R. A., "Chromophore structure in bacteriorhodopsin's $N$ intermediate: Implications for the proton-pumping mechanism", Biochemistry 27, 7097 (1988).

Glaeser, R. M., "Radiation damage and biological electron microscopy", in: Physical aspects of electron microscopy, Siegel, B. M. \& Beaman, D. R. eds. (John Wiley \& Sons, New York), 205 (1975).

Glaeser, R. M., Baldwin, J., Ceska, T. A. and Henderson, R., "Electron diffraction analysis of the $M_{412}$ intermediate of bacteriorhodopsin", Biophysics J. 50, 913 (1986). 
Harris, G., Renthal, R., Tuley, J. \& Robinson, N., "Dansylation of bacteriorhodopsin near the retinal attachment site", Biochem. Biophys. Res. Commun. 91, 926 (1979).

Henderson, R., "The structure of the purple membrane from Halobacterium halobium, analysis of the X-ray diffraction pattern", J. Mol. Biol. 93, 123 (1975).

Henderson, R., Baldwin, J. M., Downing, K. H., Lepault, J. \& Zemlin, F., "Structure of purple membrane from Halobacterium halobium: recording, measurement and evaluation of electron micrographs at $3.5 \AA$ resolution", Ultramicroscopy 19,147 (1986).

Henderson, R. \& Unwin, P. N. T., "Three dimensional model of purple membrane obtained by electron microscopy", Nature 257, 28 (1975).

Huang,K. S., Bayley, H. \& Khorana, H. G., "Delipidation of bacteriorhodopsin and reconstitution with exogeneous phospholipid", Proc. Nat. Acad. Sci. 77, 323 (1980).

Huang, K. S., Radhakrishnan, R., Bayley, H. and Khorana, H. G., "Orientation of retinal in bacteriorhodopsin as studied by cross-linking using a photosensitive analog of retinal", J. Biol. Chem. 257, 13616 (1982).

Jap. B. K., "High-resolution electron diffraction of reconstituted PhoE porin", J. Mol. Biol.199, 299 (1988).

Jap, B. K. and Kong, S-H., "Secondary structure of halorhodopsin", Biochemistry 25, 502 (1986):

Jap, B. K., Maestre, M. F., Hayward, S. B. \& Glaeser. R. M., "Peptidechain secondary structure of bR", Biophys. J. 43, 81 (1983). 
Kates, M., Kushwaha, S. C. \& Sprot, G. D., "Lipids of purple membrane from extreme halophiles and of methanogenic bacteria", Meth. in Enz. 88, 98 (1982).

Katre, N. V. \& Stroud, R. M. " A probable linking sequence between two transmembrane components of bacteriorhodopsin", FEBS Letters 36, 170 (1981).

Khorana, H. G., Gerber, G. E., Herlihy, W. C., Grant, C. P., Anderess, R. J., Nihel, \& Bieman, K., "Amino acid sequence of bacteriorhodopsin", Proc. Nat. Acad Sci., 76, 5046 (1979).

Kouyama, T., Kimura, Y., Konosita, K. and Itegami, A., "Location and orientation of the chromophore in bacteriorhodopsin', J. Mol. Biol. 153, 337 (1981).

Kuschmitz, D., and Hess, B., "Spectroscopic methods for protonation state determination", Methods in Enzymol. 88, 254 (1982).

Krimm, S. \& Dwivedi, A. M., "Infrared spectrum of purple membrane: clue to a proton conduction mechanism", Science 216,407 (1982).

Kushner, D. J., "Halophilic bacteria", Adv. Appl. Microbiol., 10, 73 (1968).

Kyte, J. and Doolittle, R. F., "A simple method for displaying the hydrophobic character of a protein." J. Mol. Biol. 157, 105. (1982).

Lanyi, J. K., "Light-dependent trans to cis isomerization of the retinal in halorhodopsin", FEBS Letters 175, 337 (1984)

Lanyi, J. K., "Halorhodopsin: A light-driven chloride pump", Ann. Rev. Biophys. Biophys. Chem., 15, 11 (1986). 
Lemke, H. D. \& Oesterhelt, D., "The role of tyrosine residues in the function of bacteriorhodopsin: specific nitration of tyrosine 26", Eur. J. Biochem. 115, 595 (1982).

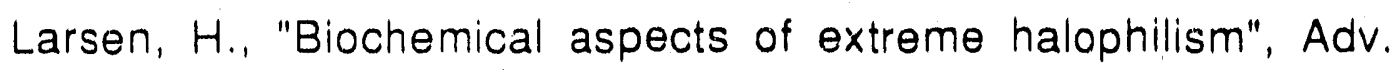
Microbiol. Physiol., 1, 97 (1973).

Lewis, B. A., Harbison, G. S., Herzfeld, J. \& Griffin, R. G., "NMR structural analysis of a membrane protein: bacteriorhodopsin peptide back bone orientation and motion", Biochemistry 24 , 4671 (1985).

Lindley, E. V. \& MacDonald, R. E., "A second mechanism for sodium extrusion in Halobacterium halobium: a light-driven sodium pump", Biochem. Biophys. Res. Commun. 88, 491 (1979).

Liao, M. J. \& Khorana, H. G., "Removal of the carboxyl-terminal peptide does not affect refolding or function of bacteriorhodopsin as a light-dependent proton pump", J. Biol. Chem. 259, 4194 (1984).

Lo, K-M., Jones, S., Hackett, N. R. and Khorara, H., "Specific amino acid substitutions in bacteriorhodopsin", Proc. Natl. Acad. Sci. $81,2285(1984)$

Long. M. M., Urry, D. W. and Stoecknius, W., "Circular dichroism of biological membranes: purple membrane of Halobacterium halobium", Biochem. Biophys. Res. Commun. 75, 725 (1977).

MacDonald, R. E., Green, R. V., Clark, R. D. \& Lindley, E. V., "Characterization of the light-driven sodium pump of Halobacteriu n halobium", J. Biol. Chem. 254, 11831 (1979).

Mao, D. and Wallace, B., "Differential light scattering and absorption flattening optical effects are minimal in the circular 
dichroism spectra of small unilamellar vesicles", Biochemistry 23, 2667 (1984).

Mast, R. C. and Haynes, L. V., "The use of the fluorescent probes perylene and magnesium 8-anillinonaphthalene-1 sulfonate to determine the CMC of surfactants in aqueous solutions", J. Co!! Int. Sci 53, 35 (1975).

Michel, H., Oesierhelt, $\mathrm{C}$. and Henderson, R., "Orthorhombic twodimensional crystal form of purple membrane", Proc. NatL. Acad. Sci. 77, 338 (1980).

Morowitz, H. J., "Proton semiconductors and energy transduction in biological systems", Am. J. Physiol. 235(3), R99 (1978). Mullen, E., Johnson, A. H. and Akhtar, M., "The identification of Lys 216 as the retinal binding residue in bacteriorhodopsin", FEBS Letters 130, 187 (1981).

Nagle, J. F. \& Morowitz, H. J., "Molecular mechanism for proton transport in membranes", Proc. Nat, Acad, Sci. 75, 298 (1978). Nakanishi, K., Balogh-Nair, V., Arnaboldi, M., Tsujimoto, K. and Honig, B., "An external point-charge model for bacteriorhodopsin to account for its purple color", J. AM. Chem. Soc. 102, 7945 (1980).

Oesterhelt, D., Hegemann, P., \& Tittor, J., "The photocycle of the chloride pump hR. II: quantum yields and a kinetic model", EMBO J. 4,2351 (1985).

Oesterhelt, D. \& Stoecknius, W., "Isolation of the cell membrane of $H$. halobium and its fractionation into red and purple membrane", Methods in Enzymology, '⿳ol. 31 (1974). 
Ogurusu, T., Maeda, A. \& Yoshizawa, T., "Absorption spectral properties of purified halorhodopsin", J. Biochem. (Japan) 95, 1073 (1984).

Ovchinikov, Yu. A., "Rhodopsin and bacteriorhodopsin: structurefunction relationships", FEBS Letters 148, 179 (1982).

Ovchinikov, Yu. A., Abdulaev, N. G., Feigina, M. Yu., Kiselev \& A. V., Lobanov,N., "The structural basis of the functioning of bacteriorhodopsin: An overview.", FEBS Letters, 100, 219 (1979).

Popot, J., Cartaud, J. and Changeux, J. P., "Reconstitution of a functional acetylcholine receptor", Eur, J. Biochem. 118, 203 (1981).

Rehorek, M. and Heyn, M. P., "Binding of all-trans retinal to the purple membrane", Biochemistry 13, 3350 (1979).

Renard, $M$, \& Delmelle, M., "Quantum efficiency of light-driven proton extrusion in Halobacterium halobium: pH dependence" , Biophy's. J., 32, 993 (1980).

Renthal, R., Dawson, N. \& Villarreal, L., "Lysine -induced reaction of Dicyclohexylcarbodiimide with bR", Biochem. Biophys. Res. Commun. 101, 653 (1981).

Renthal, R., Dawson, N., Tuley, J., and Horowitz, P., "Constraints on the flexibility of bacteriorhodopsin's carboxy-terminal tail at the purple membrane surface", Biochemistry 22, 5 (1983).

Renthal, R., Cothran, M., Espinoza, B., Wall, K. and Bernard, M., "Light activates the reaction of bacteriorhodopsin aspartic acid-115 with dicyclohexylcarbodiimide", Biochemistry 24, 4275 (1985). 
Rosenthal, K. S. \& Koussale, F., "Critical micelle concentration determination of nonionic detergents with coomassie brillant blue G-250", Anal.Chem. 55, 1115 (1983).

Rothschild, K. J. \& Clark, N. A., "Polarized infrared spectroscopy of oriented purple membrane", Biophys. J. 25, 473 (1979).

Seiff, F., Westerhausen, J., Wallat, I. and Heyn, M. P., "Location of the cyclohexene ring of the chromophore of bacteriorhodopsin by neutron diffraction with selectively deuterated retinal', Proc. Natl. Acad. Sci. 83, 7746 (1986).

Shobert, B. \& Lanyi, J. K., "Halorhodopsin is a light-driven chloride pump.", J. Biol. Chem., 257, 10306 (1982).

Shobert, B., Lanyi, J. K. \& Oesterhelt, D., "Structure and orientation of halorhodopsin in the membrane: a proteslytic fragmentation study", EMBO J 7, 905 (1988).

Smith, P. K., Krohn, R. I., Hermanson, G. T., Mallia, A. K., Gartner, F. H., Provenzano, M. D., Fujimoto, E. K., Goeke, N. M., Olson, B. J. \& Klenk, D. C., "Measurement of protein using bicinchinic acid", Anal. Biochem. 150, 76 (1985).

Smith, S. O., Marvin, M. J., Bogomolni, R. A. \& Mathies, R. A., "Structure of the retinal chromophore in the hR578 form of halorhodopsin", J. Biol. Chem. 259, 12326 (1984).

Spudich, E. N. \& Spudich, J. L., "Control of transmembrane ion fluxes to select halorhodopsin-deficient and other energytransduction mutants of Halobacterium halobium". Proc. Nat. Acad. Sci. 79, 4308 (1982).

Steiner, M. \& Oesterhelt, D., "Isolation and properties of the native chromoprotein halorhodopsin", EMBO J. 2, 1379 (1983). 
Sugiyama, $Y$. \& Mukohata, $Y$. , "Isolation and characterization of halorhodopsin from Halobacterium halobium", J. Biochem (Japan) 96, 413 (1984).

Taylor, M. E., Bogomolni, R. A. \& Weber, H. J., "Purification of photochemically active halorhodopsin", Proc. Natl. Acad. Sci. $80,6172(1983)$.

Walker, J. E., Carne, A. F. \& Schmitt, H., "The topography of the purple membrane", Nature 278, 653 (1979).

Wallace, B. A. \& Henderson, R., "Location of the carboxyl-terminus of bacteriorhodopsin in purple membrane", Biophys. J. 39, 233 (1982).

Weiss, H., Hovmoeller, S. and Leonard, K., "Preparation of membrane crystal of ubiquinol-cytochrome-c reductase from Neurospora mitochondria and structure analysis by electron microscopy", Methods in Enz. 126, 191 (1986).

Zaccai, G. \& Gilmore, D. J. "Areas of hydration in purple membrane of Halobacterium halobium: a neutron diffraction study", J. Mol. Biol. 32, 181 (1979). 

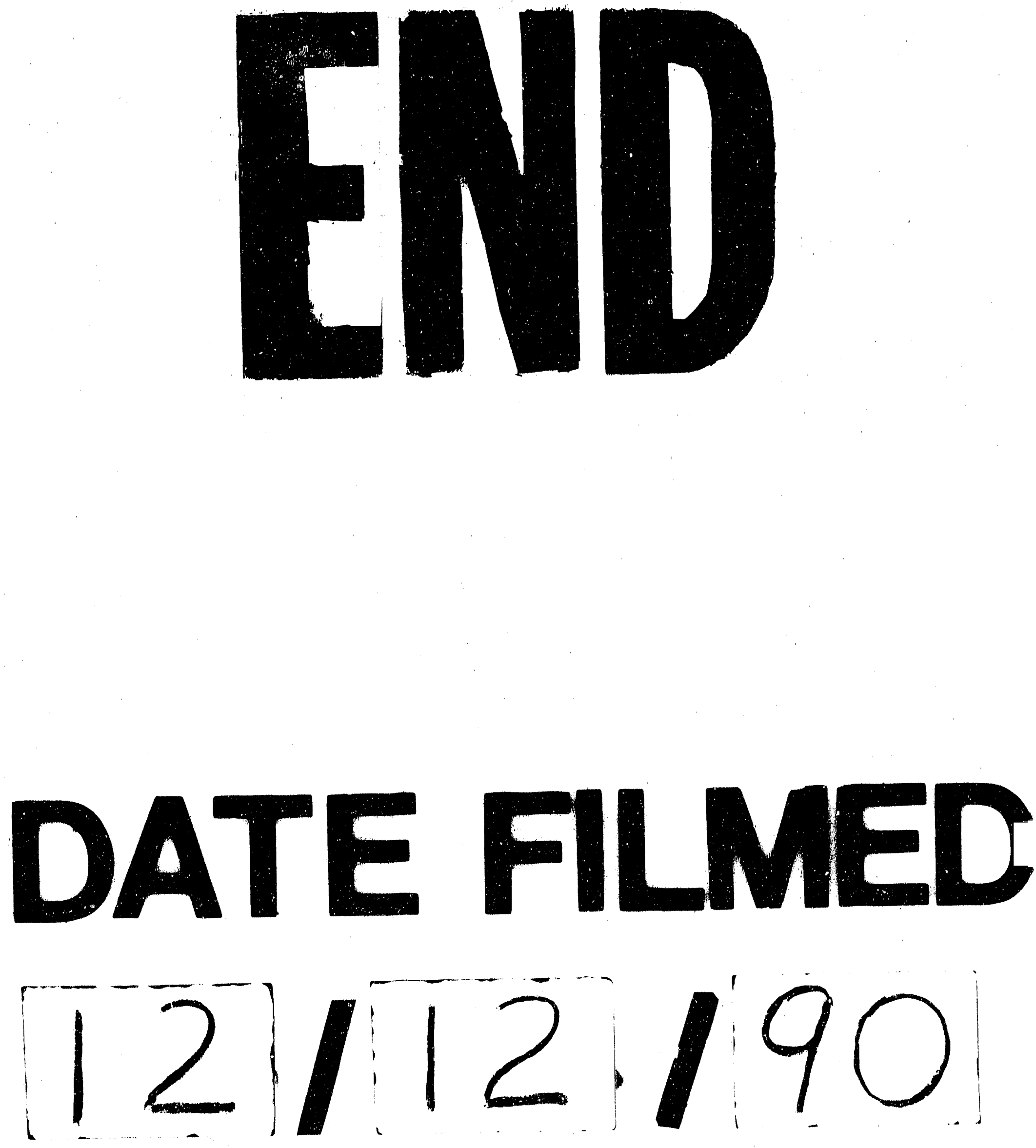


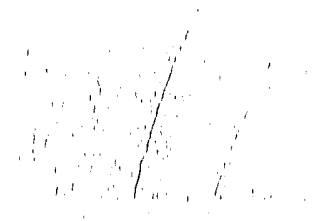

